Atmos. Chem. Phys. Discuss., 8, 14311-14346, 2008 www.atmos-chem-phys-discuss.net/8/14311/2008/ (C) Author(s) 2008. This work is distributed under the Creative Commons Attribution 3.0 License.
Atmospheric

Chemistry and Physics Discussions

This discussion paper is/has been under review for the journal Atmospheric Chemistry and Physics $(A C P)$. Please refer to the corresponding final paper in $A C P$ if available.

\title{
Implementation of a boundary layer heat flux parameterization into the Regional Atmospheric Modeling System (RAMS)
}

\section{E. L. McGrath-Spangler, A. S. Denning, K. D. Corbin, and I. T. Baker}

Department of Atmospheric Science 1371 Campus Delivery Colorado State University Fort Collins, CO 80523-1371, USA

Received: 7 May 2008 - Accepted: 22 June 2008 - Published: 25 July 2008

Correspondence to: E. L. McGrath-Spangler (emcgrath@atmos.colostate.edu)

Published by Copernicus Publications on behalf of the European Geosciences Union.

\section{ACPD}

$8,14311-14346,2008$

Implementing a PBL paramterization into

RAMS

E. L. McGrath-Spangler et al.

\section{Title Page}

Abstract

Introduction

Conclusions

References

Tables

Figures

14

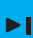

4

Back

Full Screen / Esc

Printer-friendly Version

Interactive Discussion 


\section{Abstract}

The response of atmospheric carbon dioxide to a given amount of surface flux is inversely proportional to the depth of the boundary layer. Overshooting thermals that entrain free tropospheric air down into the boundary layer modify the characteristics 5 and depth of the lower layer through the insertion of energy and mass. This alters the surface energy budget by changing the Bowen ratio and thereby altering the vegetative response and the surface boundary conditions. Although overshooting thermals are important in the physical world, their effects are unresolved in most regional models. A parameterization to include the effects of boundary layer entrainment was introduced into a coupled ecosystem-atmosphere model (SiB-RAMS). The parameterization is based on a downward heat flux at the top of the boundary layer that is proportional to the heat flux at the surface. Results with the parameterization show that the boundary layer simulated is deeper, warmer, and drier than when the parameterization is turned off. These results alter the vegetative stress factors thereby changing the carbon flux 15 from the surface. The combination of this and the deeper boundary layer change the concentration of carbon dioxide in the boundary layer.

\section{Introduction}

The planetary boundary layer $(\mathrm{PBL})$ is the layer of the atmosphere that is closest to the Earth's surface. It feels the effects of the surface through turbulent motions within the boundary layer, which work to mix the entire layer so that the characteristics of the PBL, such as the potential temperature, mixing ratio, wind speed, concentrations of trace gases, etc. are relatively homogeneous. The depth of the PBL $\left(Z_{i}\right)$ is thus important for determining the concentrations of trace gases within the layer and the exchange of the variables energy, water, momentum, and trace gases between the surface and the free atmosphere, making it a significant factor in studies of pollution, heat island effects, the general circulation and many other problems of meteorology

Implementing a PBL paramterization into RAMS

E. L. McGrath-Spangler et al.

Title Page



Introduction

Conclusions

Tables

References

Figures



Full Screen / Esc

Printer-friendly Version

Interactive Discussion 
(Stull, 1976).

In particular, the planetary boundary layer depth is important for carbon budget studies. Carbon dioxide $\left(\mathrm{CO}_{2}\right)$ is released and absorbed by land ecosystems on a daily and seasonal basis. The amount of uptake and release of carbon by plants is diluted 5 through the volume of the boundary layer so that the concentration of carbon dioxide within the boundary layer is dependent upon the PBL height.

Atmospheric inversions are a useful method for estimating surface sources and sinks of $\mathrm{CO}_{2}$ (e.g. Gurney et al., 2002; Gerbig et al., 2003a; Zupanski et al., 2007). Downstream tracer concentrations are compared to observations and used to optimize prior 10 upstream sources and sinks (Gerbig et al., 2003b; Zupanski et al., 2007). In this manner, model fluxes of $\mathrm{CO}_{2}$ are corrected with observations. The sensitivity of tracer concentrations to surface fluxes is inversely proportional to the depth of the boundary layer, so errors in $Z_{i}$ translate linearly to errors in retrieved fluxes (Denning et al., 1995, 1996b, 1999, 2008; Zhang, 2002; Gerbig et al., 2003a). These errors can lead to the 15 inaccurate estimation of carbon sources and sinks.

During the daytime, in the clear atmosphere, the surface heats up through absorption of solar radiation producing a statically unstable temperature profile. This warm surface air is positively buoyant and rises through the mixed layer in warm air plumes or thermals. Due to their momentum, rising thermals overshoot their neutral level and continue into the overlying inversion layer, becoming negatively buoyant. These thermals fall back down into the mixed layer, bringing with them warm, dry free tropospheric air that is then entrained into the boundary layer by turbulent eddies (Stull, 1976, 1988; Sullivan et al., 1998).

Entrainment causes the boundary layer to grow through the insertion of energy 25 through heat transport and mass from the free troposphere (Sullivan et al., 1998). Through the same process, turbulent kinetic energy (TKE, defined as $\frac{1}{2}\left(\overline{u^{\prime 2}}+\overline{v^{\prime 2}}+\overline{W^{\prime 2}}\right.$ ) where $u, v$, and $w$ are the horizontal and vertical components of the wind and overbars and primes indicate the mean and departures from that mean respectively) is exported into the overlying inversion, making it turbulent and thus directly a part of the plane-

\section{Implementing a PBL paramterization into RAMS}

E. L. McGrath-Spangler et al.

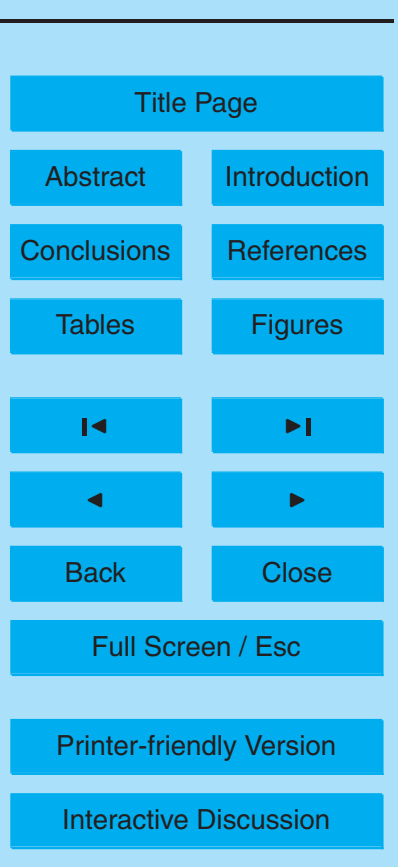


tary boundary layer. The mixing process of boundary and inversion layers also blends characteristics of the free troposphere and boundary layer, modifying such variables as wind speed and concentrations of trace gases like $\mathrm{CO}_{2}$ (Stull, 1976).

The boundary layer is the volume through which surface $\mathrm{CO}_{2}$ exchange occurs. As 5 this layer deepens, the effect of carbon assimilation is diluted through a greater volume. This means that for equal rates of assimilation, a deeper boundary layer exhibits a smaller decrease in the concentration of carbon. The temperature and humidity conditions of the boundary layer not only affect the energy budget of the layer, but also the physiological state of the vegetation. As temperatures increase and humidity de10 creases, the plants can begin to show signs of stress. This decreases the assimilation of carbon and higher soil temperatures increase heterotrophic respiration. All of these effects combine to modify $\mathrm{CO}_{2}$ concentrations near the surface. The importance of including the effects of overshooting thermals in modeling studies thus becomes apparent if the concentration of carbon in the boundary layer or the behavior of the surface vegetation is vital to the study.

Mesoscale meteorological modeling usually uses a resolution too coarse to resolve the overshooting thermals and thus does not capture the entrainment process at the top of the boundary layer (Ayotte et al., 1996; Gerbig et al., 2003a); consequently, these models cannot accurately describe the convective boundary layer (André et al., 1978). The horizontal scale of boundary layer thermals is about $1.5^{\star} Z_{i}$ or on the scale of $100 \mathrm{~m}$ to $2 \mathrm{~km}$ (Stull, 1988). According to Pielke (1991), at least four grid increments are required to represent an atmospheric feature reasonably. This means that, at best, the horizontal grid increment of the mesoscale model would need to be $500 \mathrm{~m}$ and sometimes as fine as $25 \mathrm{~m}$. Currently, model simulations with this resolution are too computationally expensive for large model domains and over long periods of time and cannot be done to fully resolve boundary layer thermals.

Since one of the most important roles of any model is to represent entrainment (Ayotte et al., 1996), several attempts have been made to understand entrainment better through large eddy simulations (LES) (Sullivan et al., 1998; Stevens and Bretherton,

\section{Implementing a PBL paramterization into RAMS}

E. L. McGrath-Spangler et al.

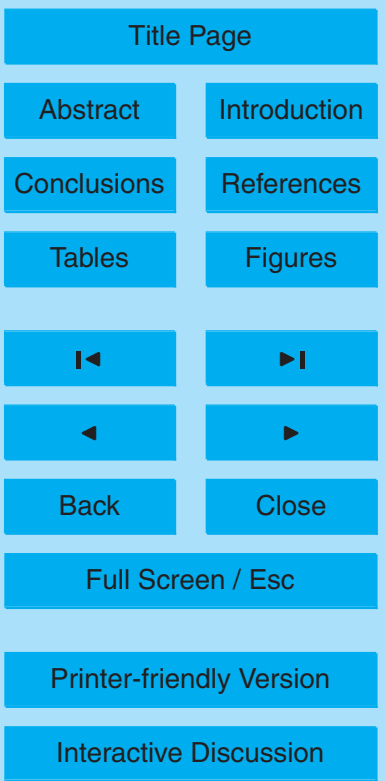


1999) and through laboratory experiments (Sayler and Breidenthal, 1998). These studies conclude that overshooting thermals play a crucial role in entrainment mechanics and that the strength of entrainment varies with atmospheric conditions. Unfortunately, atmospheric observations of entrainment rates are difficult because of mesoscale vari5 ations and coupling between physical processes (Sullivan et al., 1998).

In the current formulation of the Brazilian version of the Regional Atmospheric Modeling System (BRAMS) version 2.0, there is no parameterization to account for entrainment at the top of the boundary layer (Freitas et al., 2006). The boundary layer depth is diagnosed from the virtual potential temperature profile by finding the lowest layer 10 where the virtual potential temperature profile increases by a specified amount $(0.5 \mathrm{~K}$ in these simulations), indicating the capping inversion.

In RAMS, the vertical eddy diffusivities for momentum, heat, and TKE are inversely proportional to the vertical gradient of potential temperature through an equation for the turbulent length scale for stable conditions by André et al. (1978). They admit that 15 this parameterization is crude and not elaborate enough to describe the turbulence in a strongly thermally stratified environment. As the stratification increases, the turbulent length scale and the vertical eddy diffusivities decrease, increasing the TKE eddy dissipation term, and can do so enough to prevent vertical mixing. The temperature inversion at the top of the boundary layer can then act similar to a material surface and retard the exchange of energy and mass that occurs in the physical world. If the simulated boundary layer is too cold and too moist with a shallow boundary layer when compared to observations, an entrainment parameterization to include the effects of overshooting thermals will produce better results.

This paper discusses the implementation of an entrainment parameterization into BRAMS based on a closure assumption for the heat flux at the base of the capping inversion that warms, dries, and increases the depth of the boundary layer. The parameterization includes a tunable coefficient that is allowed to vary in the different simulations, and comparisons are presented that show the effects of changing this coefficient. Section 2 is a description of the model setup. Section 3 discusses the parameterization

\section{Implementing a PBL paramterization into RAMS}

E. L. McGrath-Spangler et al.

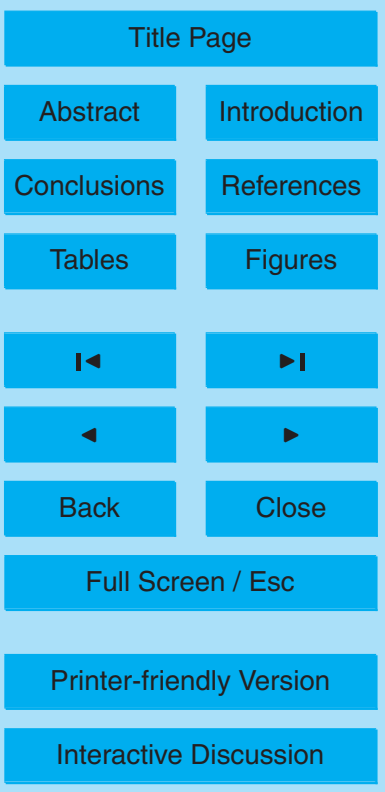

\section{5}


itself and its implementation into RAMS. Results of model simulations using the parameterization are given in Sect. 4. A conclusion and direction for future work is presented in Sect. 5.

\section{Model setup}

5 The parameterization has been implemented in a modified form of RAMS version 5.04 called BRAMS version 2.0. The major differences between RAMS and BRAMS are the implementation of the Grell convection scheme and the shallow convection scheme (Walko et al., 2002). The surface model used is the third version of the Simple Biosphere Model (SiB3), initially developed by Sellers et al. (1986). The coupling of the surface model and atmospheric model is called SiB-RAMS (Denning et al., 2003; Nicholls et al., 2004; Wang et al., 2007; Corbin et al., 2008).

RAMS was initially developed at Colorado State University as a non-hydrostatic three-dimensional model in order to study mesoscale and cloud-scale phenomena (Pielke, 1974; Tripoli and Cotton, 1982; Pielke et al., 1992; Cotton et al., 2003). It 15 includes time-dependent equations for velocity, ice-liquid water potential temperature, total water mixing ratio and diagnostic formulations of potential temperature and vapor mixing ratio (Denning, et al., 2003) on either a terrain-following $\sigma_{z}$ coordinate system or the Adaptive Aperature (ADAP) coordinate system. The ADAP coordinate is a fully Cartesian grid in which the grid cells are allowed to intersect the topography and allows partial grid cells along the topography (Walko et al., 2002). The terrain-following coordinate system is used in the simulations discussed in this paper, but the implemented parameterization accommodates both systems.

The lowest vertical level of RAMS, called the reference level, provides temperature, vapor pressure, wind velocity, pressure, precipitation, and $\mathrm{CO}_{2}$ concentrations as upper boundary conditions to SiB3. The RAMS model also provides the direct and diffuse components of short wave and near infrared radiation incident at the surface through its radiation scheme (Harrington 1997). These input variables to SiB3 are updated

Implementing a PBL paramterization into RAMS

E. L. McGrath-Spangler et al.

Title Page

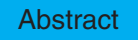

Introduction

Conclusions

Tables

References

Figures

14

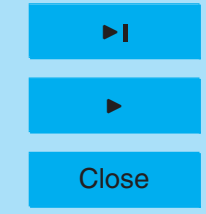

Back

Full Screen / Esc

Printer-friendly Version

Interactive Discussion 
every model timestep. In return, SiB3 produces surface latent and sensible heat fluxes $\left.\overline{\left(w^{\prime} \theta_{v}^{\prime}\right.}\right|_{s}$ and $\left.\overline{w^{\prime} r_{v}^{\prime}}\right|_{s}$ where $\theta_{v}$ and $r_{v}$ are the virtual potential temperature and mixing ratio respectively and $s$ represents the surface), vertical fluxes of carbon dioxide at the surface $\left(\left.\overline{W^{\prime} C^{\prime}}\right|_{s}\right.$ where $C$ is the $\mathrm{CO}_{2}$ concentration), momentum fluxes $\left(\left.\overline{u^{\prime} W^{\prime}}\right|_{s}\right)$, and 5 upward long- and short-wave radiation. These variables are then inputs to RAMS at the reference level (Denning, et al., 2003) and serve as a lower boundary condition.

The turbulence closure option used during these simulations was the Mellor and Yamada (1982) scheme for vertical diffusion. Mellor and Yamada is a local option that employs a prognostic turbulent kinetic energy. The Smagorinsky (1963) scheme uses a deformation-based mixing coefficient and was used for horizontal diffusion. This option can be used for mesoscale simulations when turbulent boundary layer eddies cannot be resolved (Nicholls et al., 2004).

Plant and plant photosynthesis are parameterized in the SiB model in an attempt to mimic the real world. SiB is a land-surface parameterization used to compute biophys15 ical exchanges in climate models (Sellers et al., 1986), but also includes ecosystem metabolism (Sellers et al., 1996; Denning et al., 1996a). The photosynthesis parameterization was originally developed by Farquhar et al. (1980).

The parameterization assumes the leaf assimilation rate is the minimum of three limiting rates (Collatz et al., 1991, 1992). These are: (1) efficiency of the photosynthetic enzyme system (Rubisco limited), (2) amount of photosynthetically active radiation (PAR) captured by leaf chlorophyll (light limited), and (3) capacity of the leaf to export or utilize the products of photosynthesis (for C3 plants) and PEP-Carboxylase limitation (for $\mathrm{C} 4$ plants). The first and third limiting rates are functions of the canopy temperature and root zone soil wetness. Photosynthesis also depends upon the $\mathrm{CO}_{2}$ 25 concentration within the leaf and the relative humidity at the leaf surface through the leaf conductance. The leaf conductance is directly proportional to the relative humidity and inversely proportional to the $\mathrm{CO}_{2}$ concentration and can be thought of as how open are the stomata. The larger the leaf conductance is allowed to become, the more carbon is assimilated by the leaf and the greater the rate of photosynthesis (Sellers et

\section{Implementing a PBL paramterization into RAMS}

E. L. McGrath-Spangler et al.

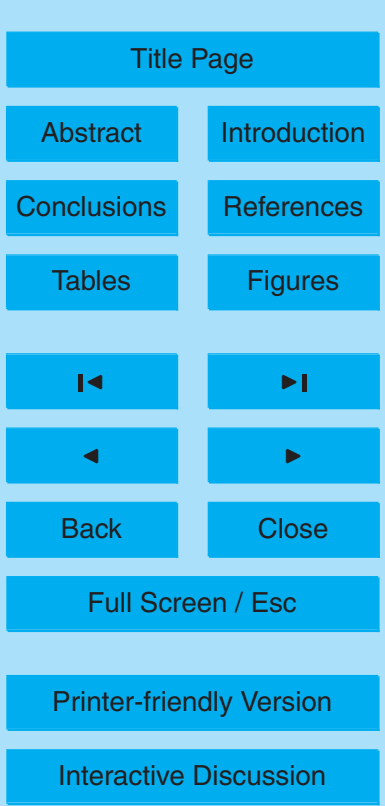

14317 
al., 1996). This parameterization of plant photosynthesis in the model controls how the surface characteristics are altered by the entrainment parameterization that is the topic of this paper.

A single grid was used on a domain of $200 \times 200 \mathrm{~km}$ with 25 individual grid cells $5(5 \times 5)$ with a size of $40 \times 40 \mathrm{~km}$ each, centered at $45^{\circ} \mathrm{N}$ and $90^{\circ} \mathrm{W}$. This grid spacing allows the resolution of mesoscale features, but is much too coarse to resolve the individual thermals that entrain free atmospheric air into the boundary layer. Fortytwo vertical grid levels were used with the lowest level at about $30 \mathrm{~m}$ and extending up to a domain top of $4 \mathrm{~km}$ with a vertical grid stretch ratio of roughly 1.1. Additional 10 levels were included between $1500 \mathrm{~m}$ and $2200 \mathrm{~m}$ to produce an average layer depth of about $70 \mathrm{~m}$. This was done to increase vertical resolution near a common boundary layer depth in order to resolve variations in the effects of the parameterization due to varying values of the tunable parameter.

Cyclic boundary conditions were used to isolate local processes that control PBL 15 depth. Since the domain was periodic, large-scale advective influences were not included. The domain characteristics were horizontally homogeneous so that there were no influences from surface heterogeneity and no weather systems were allowed to advect into the domain. The only acting forces were those associated with the diurnal cycle and the parameterization itself. This setup also allowed the runs to be compu20 tationally inexpensive and quick to run. The simulation was allowed to run for $72 \mathrm{~h}$. The emphasis of this setup was to produce a simplified and idealized case in order to isolate the effects of the entrainment parameterization. It therefore does not resemble any particular event and model responses should be considered in this context.

The vertical profiles of pressure, temperature, humidity, and wind velocity were ini25 tialized horizontally homogeneously from a relatively cool August sounding, typical of Green Bay, Wisconsin at $44.48^{\circ} \mathrm{N}$ and $88.13^{\circ} \mathrm{W}$ with winds predominately out of the west and northwest. The topography was defined as flat and at sea level everywhere in the domain, removing any effects of terrain on boundary layer depth or growth. Similarly, the vegetation, soil textural class, fraction of photosynthetically active radiation

\section{Implementing a PBL paramterization into RAMS}

E. L. McGrath-Spangler et al.

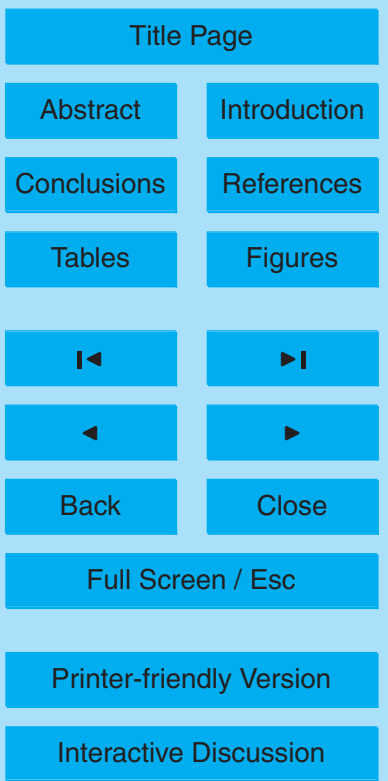


(FPAR), and leaf area index (LAI) were all prescribed as horizontally homogeneous. The vegetation type was C3 tall broadleaf and needleleaf trees while the soil type was loam. The default FPAR and LAI used were 0.93 and 6.2 , respectively. In order to isolate the effects of dry convection, all water present in the model had to remain as water 5 vapor, even if supersaturation occurred, in order to prevent the formation of clouds and precipitation. Clouds would have inhibited convective growth of the boundary layer.

\section{Entrainment parameterization and implementation}

The temperature profile in the well-mixed boundary layer can be assumed constant in time $\left[\frac{\partial}{\partial t}\left(\frac{\partial \theta_{v}}{\partial z}\right)=0\right.$ where $t$ is time and $z$ is the vertical direction] as the boundary layer warms because of the turbulent mixing throughout that layer, assuming radiative heating is independent of height. This implies that the heat flux throughout the boundary layer is linear with height, otherwise part of the layer would change temperature at a different rate from another part, and the temperature profile would not be constant in time and the layer would no longer be well-mixed. At the inversion interface, over15 shooting thermals inject cool, moist, $\mathrm{CO}_{2}$-depleted turbulent boundary layer air into the overlying inversion and entrain warm, $\mathrm{CO}_{2}$-rich free tropospheric air downward creating negative heat and carbon fluxes in the region of overshoot. Since the mixed layer is heated both from the surface due to solar heating and from the top of the boundary layer by entrainment, the profile of heat flux throughout the boundary layer is linear 20 (Stull, 1976). Above the inversion, the perturbation vertical velocity is assumed zero, implying the heat flux is also zero.

This implies that the negative heat flux at the base of the capping inversion $\left(\left.\overline{w^{\prime} \theta_{v}{ }^{\prime}}\right|_{z i}\right)$ is linearly proportional to the heat flux at the surface, leading to the closure assumption for the heat flux at the top of the boundary layer:

$\left.{ }_{25} \overline{w^{\prime} \theta_{v}{ }^{\prime}}\right|_{z i}=-\left.\alpha \overline{w^{\prime} \theta_{v}{ }^{\prime}}\right|_{s}$

\section{ACPD}

$8,14311-14346,2008$

\section{Implementing a PBL} paramterization into

RAMS

\section{E. L. McGrath-Spangler} et al.

\section{Title Page}

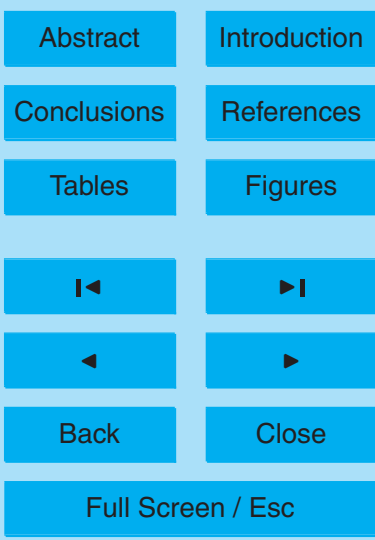

Printer-friendly Version

Interactive Discussion 
where $\alpha$ is the proportionality constant (Stull, 1988). Estimates of $\alpha$ from experimentation and theory range anywhere from zero to one with most published values being between 0.1 and 0.3 (e.g. Betts, 1973; Carson, 1973; Deardorff, 1974; Rayment and Readings, 1974; Willis and Deardorff, 1974; Stull, 1976; Davis et al., 1997; Sullivan et 5 al., 1998; Yi et al., 2001).

This assumption was used to include a heat flux and a flux of other variables such as wind velocity and carbon dioxide concentration from overshooting thermals to alter the temperature, water vapor mixing ratio, winds, and $\mathrm{CO}_{2}$ mixing ratios of the boundary layer and the lowest layer of the inversion. The heat flux can be used to define a time 10 rate of change of potential temperature for the layers just above and just below the base of the inversion:

$$
\frac{\partial \theta}{\partial t}=\frac{\left.\alpha \overline{w^{\prime} \theta_{v}{ }^{\prime}}\right|_{s}}{\Delta z} \text {. }
$$

where $\Delta z$ is the thickness of the layer. Through this heating at the top of the boundary layer, the whole mixed layer warms through turbulent mixing whereas the inversion layer cools. This process weakens the capping inversion and makes it easier for the boundary layer to grow.

The heat flux across the capping inversion can be used to define a mass flux representative of the amount of mixing between the layers surrounding the interface between the boundary layer and the capping inversion required to produce these temperature 20 changes. This mass flux is given by:

$M=\frac{\left.\rho \alpha \overline{w^{\prime} \theta_{v}{ }^{\prime}}\right|_{s}}{\Delta \theta_{v}}$

where $\rho$ is the density of the air and is computed from the total Exner function and ice-liquid potential temperature prognosed by RAMS (Medvigy et al., 2005). This gives the mass flux the units of $\mathrm{kg} \mathrm{m}^{-2} \mathrm{~s}^{-1}$. When multiplied by the specific humidity of the

\section{Implementing a PBL paramterization into RAMS}

E. L. McGrath-Spangler et al.

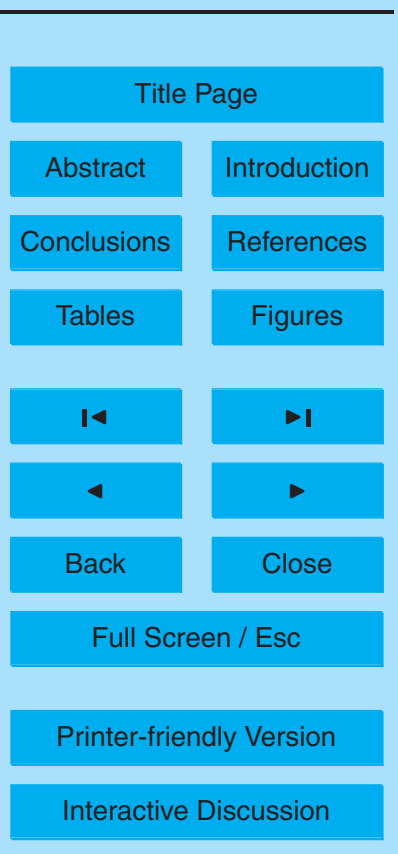


layer, $q_{v}$, this becomes a mass flux of water vapor. This can be used to find a time rate of change of the mixing ratio for the layers above and below the interface given by:

$\frac{\partial r_{v}}{\partial t}=-\frac{\left.\alpha q_{v} \rho \overline{w^{\prime} \theta_{v}{ }^{\prime}}\right|_{s}}{\Delta \theta_{v} \rho_{\text {dry }} \Delta z}$

where $\rho_{\text {dry }}$ is the density of the dry air. This induces a drying of the whole boundary 5 layer through turbulent mixing and a moistening of the capping inversion.

This same mass flux can be used to define time rates of change of the different components of the wind vector, $T K E$, and $\mathrm{CO}_{2}$ concentration given in the equations below.

$\frac{\partial u_{i}}{\partial t}=\frac{\left.u_{i} \alpha \overline{w^{\prime} \theta_{v}{ }^{\prime}}\right|_{s}}{\Delta \theta_{v} \Delta z}$

${ }_{10} \frac{\partial w}{\partial t}=-\frac{\left.w \alpha \overline{w^{\prime} \theta_{v}{ }^{\prime}}\right|_{s}}{\Delta \theta_{v} \Delta z}$

$\frac{\partial T K E}{\partial t}=-\frac{\left.T K E \alpha \overline{w^{\prime} \theta_{v}^{\prime}}\right|_{s}}{\Delta \theta_{v} \Delta z}$

$\frac{\partial C}{\partial t}=\frac{\left.C \alpha \overline{w^{\prime} \theta_{v}^{\prime}}\right|_{s}}{\Delta \theta_{v} \Delta z}$

In these equations, $u_{i}$ represents the two components of the horizontal wind vector. These equations represent the mixing across the overlying capping inversion and in15 troduce negative fluxes of horizontal momentum and $\mathrm{CO}_{2}$ concentration and positive vertical fluxes of vertical velocity and TKE.

Equations (2), (4), (5), (6), (7), and (8) are included in a parameterization within the shallow cumulus convection parameterization unique to BRAMS (Walko et al., 2002;

ACPD

$8,14311-14346,2008$

Implementing a PBL paramterization into

RAMS

E. L. McGrath-Spangler et al.

Title Page

Abstract

Introduction

Conclusions

Tables

References

Figures

14

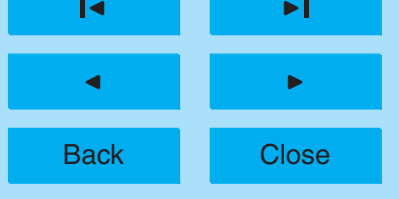

Full Screen / Esc

Printer-friendly Version

Interactive Discussion 
Freitas et al., 2006). The boundary layer height is diagnosed from the virtual potential temperature profile as the height where the temperature increases by $0.5 \mathrm{~K}$, defining the capping inversion. After the PBL height is determined by this method, the temperature, mixing ratio, wind velocity, $T K E$, and carbon dioxide concentration tendencies for 5 the layers above and below $Z_{i}$ are altered by the above equations. Before the end of the timestep, the seven variables are updated by their respective tendency arrays.

\section{Results}

\subsection{Physical effects}

Inclusion of a parameterization for boundary layer entrainment due to overshooting 10 thermals results in a deeper boundary layer as is evident in Fig. 1. The greater depth is a product of the input of heat energy from the overlying inversion and the upward transport of turbulent kinetic energy, physically incorporating the lowest levels of the inversion into the boundary layer. The modeled boundary layer is allowed to grow as long as the surface sensible heat flux is positive. Once it becomes negative, an 15 inversion is formed and the boundary layer collapses. The discretized nature of the model does not allow the boundary layer to grow in a smooth way as it would in the physical world. $Z_{i}$ is limited by the predetermined model levels and can only change when enough energy is present to move from one level to the next.

Figure 2 shows the vertical profile of potential temperature at 17:00 UTC (12:00 LT) on the first full day of simulation. Throughout the depth of the boundary layer, the entraining case is warmer than the control case by a few degrees. In the middle of the layer, the entraining case is $3.5 \mathrm{~K}$ warmer for an increase of just over $1 \%$. However, the inversion is slightly cooler in the entraining case, almost $0.3 \%(0.84 \mathrm{~K})$ cooler. The combination of a warmer mixed layer and a weaker capping inversion means that it is easier for overshooting thermals to break through the inversion and grow the boundary layer through entrainment. In addition, since the boundary layer is warmer, less surface

Implementing a PBL paramterization into RAMS

E. L. McGrath-Spangler et al.

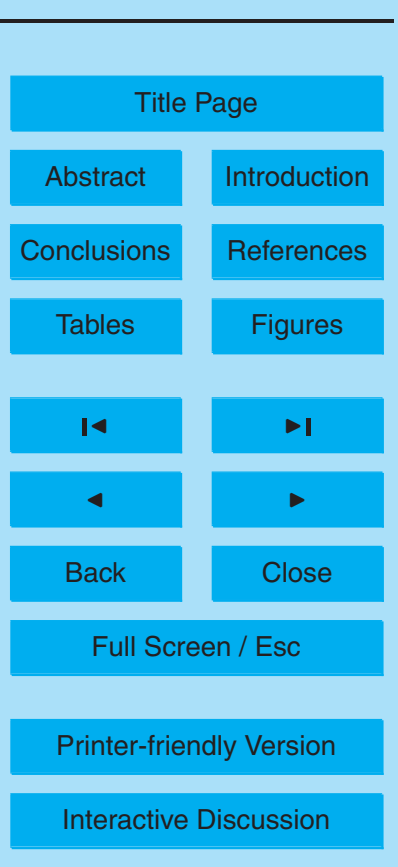

\section{2}


heating is required to erode the inversion and grow the boundary layer. Turbulent mixing within the boundary layer distributes this warming throughout its depth.

The stronger TKE in the entraining case produces a better-mixed, closer to adiabatic thermal profile. Overall, the impact of the parameterization on the potential temperature 5 increases the depth of the boundary layer.

The water vapor mixing ratio profile is also modified by the parameterization (Fig. 3 ). In both the entraining and control cases, the highest mixing ratios are located at the surface, a result of the source of water from evaporation and transpiration being located at the surface, and gradually decrease to the top of the boundary layer where there is 10 a sharp gradient transitioning into the much drier overlying air. The upward transport of moisture, carried by the overshooting thermals, results in a drier boundary layer and a moister inversion layer in the entraining case. The change in water vapor mixing ratio in the middle of the boundary layer is about $0.66 \%\left(0.07 \mathrm{~g} \mathrm{~kg}^{-1}\right)$ decrease in the entraining case, but the greater moisture content in the overlying inversion is slightly over $1517 \%\left(1.4 \mathrm{~g} \mathrm{~kg}^{-1}\right)$ due to the low water content and shallow depth of the inversion layer. Since water vapor present in an air mass decreases the density of that air mass, the overall effect of upward advection of water vapor is to decrease the ability of thermals to penetrate the inversion and make it harder for the well-mixed layer to erode the inversion. This inhibits boundary layer growth through a reduction in the positive buoyancy of thermals originating from the surface and favors a shallower boundary layer.

The effects of the parameterization on the potential temperature and the water vapor mixing ratio act in opposite directions. In order to understand the combined effect, the profile of the virtual potential temperature must be examined. Virtual potential temperature can be related to potential temperature and water vapor mixing ratio through the 25 equation:

$\theta_{v}=\theta\left(1+0.61 r_{v}\right)$

As $r_{v}$ and $\theta$ increase, so does the virtual potential temperature. Since the virtual potential temperature is used to determine the top of the boundary layer and includes the

Implementing a PBL paramterization into RAMS

E. L. McGrath-Spangler et al.

Title Page

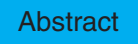

Introduction

Conclusions

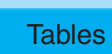

References

Tables

Figures

14

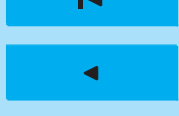

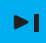

Back

Close 
effects of both potential temperature and water vapor mixing ratio, it is a direct way of determining which effect dominates.

Figure 4 shows the profile of the virtual potential temperature. The boundary layer is warmer in the entraining case and the middle of the layer is warmer by about a quarter 5 of a percent $(0.77 \mathrm{~K})$. In the inversion layer, the entraining case is still cooler than the control case by about $0.14 \%(0.4 \mathrm{~K})$. Although the effects of vertical moisture advection oppose those of temperature, the temperature effects dominate and the overall result is a vertical potential temperature profile that is less inhibitive to boundary layer growth after the influence of overshooting thermals is considered.

10 Surface variables are also affected by overshooting thermals through the mixing of boundary layer characteristics throughout the depth of the boundary layer by eddies and their associated TKE. Modification of surface variables is important when comparing the model results to observations. Figure 5 shows the temporal evolution of potential temperature in the lowest atmospheric model level. The entraining case has 15 warmer temperatures than the control case throughout the simulation. The differences increase with time such that on the third day of simulation, the daytime entraining case's potential temperature is $1.5 \mathrm{~K}$ warmer than the control case.

At night, the entraining case is much warmer than the control case, by as much as $6 \mathrm{~K}$ toward the end of the simulation. This is due, in part, to the heat capacity of the atmosphere. The daytime temperature is warmer in the entraining case and so it does not cool off as quickly resulting in a warmer nighttime temperature. A more significant cause of the warm nighttime temperatures is that the nocturnal inversion is not as strong in the entraining case. The nighttime TKE is stronger near the surface (not shown) producing a weaker nocturnal capping inversion. The weaker capping inversion allows more mixing between the surface air and the overlying residual layer. The consequence of increased mixing is that the radiatively cooled surface air is mixed with warmer overlying air and thus remains warmer.

Figure 6 shows the effects of overshooting thermals on the horizontal wind velocity near the surface. Momentum from the free troposphere is mixed downward by the over-

\section{Implementing a PBL paramterization into RAMS}

E. L. McGrath-Spangler et al.

Title Page

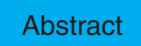

Introduction

Conclusions

Tables

References

Figures

14

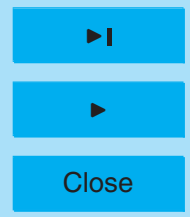

Back

Full Screen / Esc

Printer-friendly Version

Interactive Discussion 
shooting thermals. The TKE in the boundary layer mixes that momentum throughout the depth of the boundary layer and therefore adjusts the profile of the wind. The wind profile directly above the boundary layer is northwesterly and so when it is advected downward, it turns the boundary layer wind in that direction. In the lowest atmospheric 5 model level, this results in the zonal wind in Fig. 6a becoming stronger and more positive and the meridional wind in Fig. $6 \mathrm{~b}$ becoming weaker and less positive.

The temporal evolution of sensible and latent heat fluxes from the canopy air space (CAS) into the boundary layer is shown in Fig. 7a and $7 \mathrm{~b}$ respectively. The daytime sensible heat flux is smaller in the entraining case because the boundary layer is warmer 10 in this case. Sensible heat flux is proportional to the gradient in temperature between the CAS and the boundary layer so if that gradient is weakened through warming of the boundary layer, the heat flux is lessened. On the third day of simulation, the sensible heat flux of the control case is $20 \mathrm{~W} \mathrm{~m}^{-2}$ stronger. This produces a change of about $7 \%$ in the sensible heat flux resulting from the entrainment parameterization. Since 15 the parameterization is proportional to the surface heat flux, reducing this flux reduces the effects of the thermals. Conversely, the sensible heat flux at night is more strongly negative in the entraining case. The surface cools off, but the atmosphere remains warm so that the gradient in temperature is greater in the entraining case. Because the sensible heat flux is more strongly negative at night, more solar heating is required during the day to produce a positive sensible heat flux.

As was the case for potential temperature and water vapor mixing ratio, the response of sensible and latent heat fluxes to entrainment is opposed. The drier boundary layer means that the gradient in water vapor mixing ratio between the boundary layer and the CAS is stronger in the entraining case. The drier boundary layer persists throughout the diurnal cycle inducing a larger positive latent heat flux during the day and a smaller negative flux at night. As temperatures increase in the model atmosphere, the relative humidity decreases and the relative humidity gradient between the boundary layer and the CAS becomes even larger inducing an even stronger latent heat flux. A larger latent heat flux contributes to a larger total heat flux. The larger heat flux then contributes to a

\section{Implementing a PBL paramterization into RAMS}

E. L. McGrath-Spangler et al.

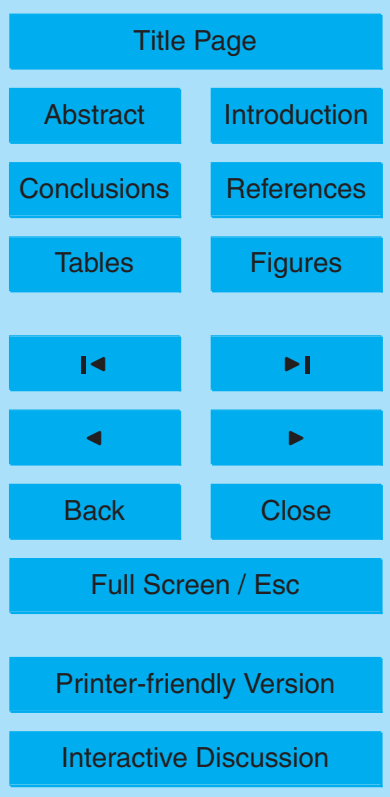

14325 
larger impact of the parameterization on the heat flux at the top of the boundary layer. At the peak of latent heat flux on the third day of simulation, the entraining case's latent heat flux is $15 \mathrm{~W} \mathrm{~m}^{-2}$ greater for a change of about $6 \%$. The additional moisture from the surface source is then mixed upward by turbulent eddies to moisten the depth of the 5 boundary layer. Although the sensible and latent heat fluxes oppose each other, the total buoyancy heat flux (not shown) is smaller in the entraining case than the control case.

\subsection{Physiological effects}

The physical modifications to the boundary layer directly impact the vegetation at the 10 surface. The energy budget of the vegetated land surface partitions net downward radiation into turbulent fluxes of heat and moisture that warm and moisten the atmosphere, plus a smaller heat flux into the soil. The Bowen ratio of sensible to latent heat fluxes is determined by the conductance of plant stomata, which is actively controlled as an evolved response by plants to maximize $\mathrm{CO}_{2}$ uptake by photosynthesis 15 while minimizing water loss (Ball et al., 1987; Collatz et al., 1991; Bonan et al., 2002). Stomatal conductance (and hence transpiration) is generally greatest when photosynthetic carbon uptake is greatest, the air is nearly saturated with respect to water vapor, and the temperature moderate. The drying influence of entrainment can produce a humidity stress on the plants so that they close their stomata, causing a response in transpiration, the surface energy budget, and photosynthetic rates (Davis et al., 1997).

Stomatal conductance and photosynthesis were calculated iteratively according to enzyme kinetics, diffusion of $\mathrm{CO}_{2}$ and water vapor, and the Ball-Berry equation (Collatz et al, 1991). Stomatal conductance is directly proportional to the relative humidity at the leaf surface (inside the laminar boundary layer surrounding the leaf), and is adjusted 25 downward by multiplying by nondimensional "stress factors" to account for non-optimal temperatures or insufficient soil moisture (Sellers et al, 1996) (Fig. 8).

Simulated stomatal conductance (Fig. 9) was reduced during the hottest part of each day due to a combination of slightly reduced humidity and high-temperature stress. En-

\section{Implementing a PBL paramterization into RAMS}

\section{E. L. McGrath-Spangler} et al.

Title Page

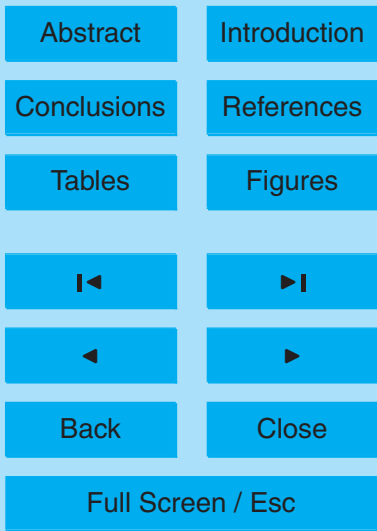

Printer-friendly Version

Interactive Discussion

\section{6}


trainment of dry air into the boundary layer by overshooting thermals is communicated through turbulent mixing, leading to a slightly warmer and drier stomatal microenvironment, and therefore reduced stomatal conductance. Note that despite the slight reduction in stomatal conductance, the simulated sensible heat flux was suppressed 5 and latent heat flux was enhanced in the entraining case due to stronger gradients in the surface layer (Fig. 7).

Figure 10 shows the impact of the vegetative stress on the net ecosystem exchange (NEE) of $\mathrm{CO}_{2}$ and its components. In the morning, warmer temperatures cause the entraining case to have very slightly enhanced uptake of carbon. High-temperature stress 10 and low humidity at mid-day produces less uptake, taking up $1.3 \mu \mathrm{mol} \mathrm{m}^{-2} \mathrm{~s}^{-1}$ less carbon by the third day. The NEE at night is very similar between the entraining and control cases with slightly greater respiration in the entraining case due to the warmer surface temperature. Ground respiration is a function of the surface soil temperature and varies with the diurnal cycle of temperature (Fig. 10b). Since the entraining case 15 is warmer throughout the simulation, the ground respiration is larger and more carbon is released into the atmosphere from soil decomposition. Warmer and drier air at midday suppresses photosynthetic assimilation (Fig. 10c). The entraining thermals in the simulation thus act indirectly on both components of the net $\mathrm{CO}_{2}$ exchange to suppress the drawdown of $\mathrm{CO}_{2}$ from the PBL through their effects on temperature and moisture.

The overall impact of simulated entrainment on $\mathrm{CO}_{2}$ in the PBL reflects the modified NEE as well as dilution through the deeper mixed layer and enhanced mixing through the PBL top. Figure 11 shows only the daytime concentration of $\mathrm{CO}_{2}$ since this study is not concerned with nighttime values. During the day, negative NEE draws down the $\mathrm{CO}_{2}$ concentration. The daily minimum in $\mathrm{CO}_{2}$ concentration occurs near sunset, just as the vegetation stops removing carbon from the atmosphere.

$\mathrm{CO}_{2}$ concentrations in the entraining case are higher than the control due to both the reduced assimilation and the depth of the boundary layer. As the boundary layer grows, a greater volume of the atmosphere is in contact with the surface. Removal of a given amount of carbon reduces the $\mathrm{CO}_{2}$ concentration less when the carbon is

\section{Implementing a PBL paramterization into RAMS}

E. L. McGrath-Spangler et al.

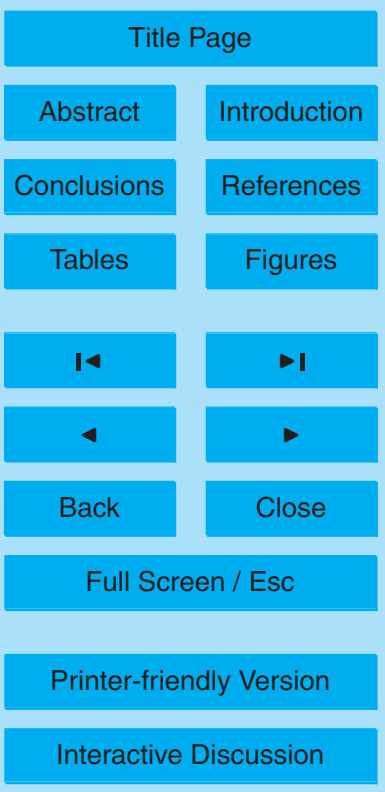

\section{7}


removed from the greater volume. A deeper boundary layer consequently results in higher carbon dioxide concentrations within the boundary layer.

\subsection{Parameterization effects}

The previous results were obtained by setting the tunable parameter, $\alpha$, to 0.20 , indi5 cating that the entrainment heat flux at the top of the boundary layer was assumed to be $20 \%$ of the surface heat flux. The following discussion determines the sensitivity of the system to varying strengths of the parameterization by using values of $\alpha$ between 0.0 and 0.5 .

Figure 12 illustrates how mid-day potential temperature (Fig. 12a), water vapor mix10 ing ratio (Fig. 12b), $\mathrm{Z}_{i}$ (Fig. 12c), and $\mathrm{CO}_{2}$ concentration (Fig. 12d) in the lowest atmospheric model level on the second day of simulation vary as functions of $\alpha$. The potential temperature linearly increases with $\alpha$, with a correlation coefficient of 0.9944 . Neglecting entrainment can result in boundary layer temperature errors that can also affect the assimilation of carbon by plants.

15 The water vapor mixing ratio linearly decreases for $\alpha$ greater than 0.10 . As $\alpha$ increases, overshooting thermals remove water from the boundary layer and transfer it to the overlying inversion. The water vapor flux has a minimum at $\alpha=0.05$ and increases up to $\alpha=0.10$. As the boundary layer dries, the moisture gradient between the CAS and the boundary layer increases, producing a greater latent heat flux. The latent heat flux moistens the boundary layer, acting contrary to the overshooting thermals. A contributing factor to this process is that the simulation is idealized and no new air is allowed to advect into the domain to reduce the amount of latent heat flux at the surface. The correlation coefficient between $\alpha$ and the water vapor mixing ratio is -0.59 and is significant at the $95 \%$ level for the range of $\alpha$ shown.

25 The boundary layer height is dependent upon the vertical grid spacing. Energy is needed for $Z_{i}$ to jump from one level to the next, and greater vertical resolution requires less energy to make a jump, but each jump is smaller. $Z_{i}$ monotonically increases with $\alpha$ and does so with a correlation coefficient of 0.96 . The boundary layer depth at this

\section{Implementing a PBL paramterization into RAMS}

E. L. McGrath-Spangler et al.



14328 
time behaves linearly with the strength of the entrainment heat flux.

Figure $12 \mathrm{~d}$ shows how $\mathrm{CO}_{2}$ concentration varies as a function of $\alpha$. As $\alpha$ increases, so also does the concentration of $\mathrm{CO}_{2}$ in the lowest model level. This can be attributed to deeper boundary layers diluting the effect of photosynthetic uptake and increased 5 vegetative stress associated with the warmer and drier conditions of an entrainment heat flux. The correlation coefficient between $\mathrm{CO}_{2}$ concentration and $\alpha$ is near unity and the increasing trend exceeds the $99.99 \%$ confidence level. With a regression coefficient of near 14.6 , the amount of variability of $\mathrm{CO}_{2}$ concentration with $\alpha$ is alarming for inversion studies that depend upon accurate modeled surface concentrations. Be-

10 tween $\alpha=0.0$ and $\alpha=0.20$, the concentration of carbon dioxide increases nearly $5 \mathrm{ppmv}$ for a change of $1.35 \%$.

\section{Conclusions and future work}

The effects of overshooting thermals are essential to studies of the carbon budget using modeling. This experiment seeks to parameterize these effects that are too fine 15 for the grid spacing of mesoscale meteorological models to resolve. These thermals warm and dry the boundary layer through entrainment of free tropospheric air and mix wind velocities, $T K E$, and $\mathrm{CO}_{2}$ concentrations. The addition of mass to the boundary layer also allows it to grow. This process weakens the capping inversion and reduces the amount of energy needed within the boundary layer for it to grow further. The increased PBL depth means that the remaining uptake of carbon is diluted through a deeper layer, increasing carbon concentrations. The mass and heat fluxes associated with overshooting thermals affect the atmospheric conditions to which the underlying vegetation respond. The altered response, in turn, affects the photosynthetic uptake of carbon thereby increasing the daytime $\mathrm{CO}_{2}$ concentration even further. Since most observations are performed within the boundary layer, neglect of this process produces a model-observation mismatch and introduces errors into the assumed distribution of sources and sinks.

\section{Implementing a PBL paramterization into RAMS \\ E. L. McGrath-Spangler et al.}

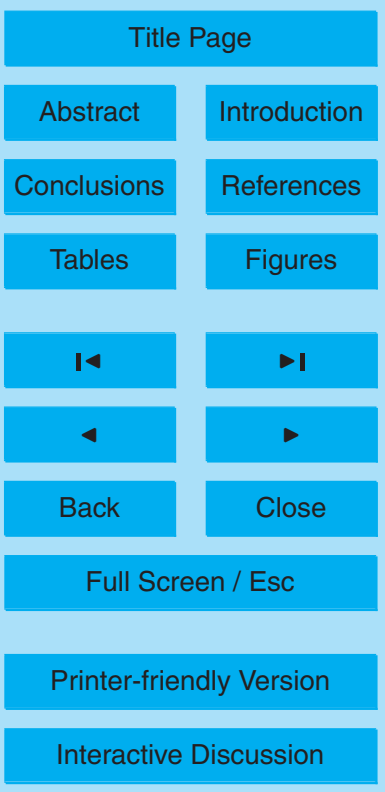


With this end in mind, the parameterization added to SiB-RAMS introduces a negative sensible heat flux and a positive water vapor flux at the top of the boundary layer and mixes the other variables. This parameterization includes a tunable parameter, $\alpha$, that is equal to the negative of the ratio of the entrainment heat flux at the top of the 5 boundary layer to the surface heat flux. The parameterization does induce a warmer, drier boundary layer that affects such characteristics as sensible and latent heat fluxes, wind velocity, and carbon dioxide concentration.

Future work will focus on evaluation of the entrainment parameterization for real cases, estimation of the entrainment parameter $\alpha$, and application to $\mathrm{CO}_{2}$ source/sink estimation.

Acknowledgements. This research was supported by National Aeronautics and Space Administration grant NNG05GD15G.

\section{References}

André, J. C., De Moor, G., Lacarrère, P., Therry, G., and Du Vachat, R.: Modeling the 24-hour evolution of the mean and turbulent structures of the planetary boundary layer, J. Atmos. Sci., 35, 1861-1883, 1978.

Ayotte, K. W., Sullivan, P. P., Andrén, A., Doney, S. C., Holtslag, A. A. M., Large, W. G., McWilliams, J. C., Moeng, C.-H., Otte, M. J., Tribbia, J. J., and Wyngaard, J. C.: An evaluation of neutral and convective planetary boundary layer parameterizations relative to large eddy simulation, Bound.-Lay. Meteorol., 79, 131-175, 1996.

Ball, J. T., Woodrow, I. E., and Berry, J. A.: A model predicting stomatal conductance and its contribution to the control of photosynthesis under different environmental conditions, Progress in Photosynthesis Research, edited by: Biggens, J., 221-224, 1987.

Betts, A. K.: Non-precipitating cumulus convection and its parameterization, Q. J. Roy. Meteor. Soc., 99, 178-196, 1973.

Bonan, G. B., Lewis, S., Kergoat, L., and Oleson, K. W.: Landscapes as patches of plant functional types: An integrating concept for climate and ecosystem models, Global Biogeochem. Cy., 16, 5.1-5.23, 2002.

\section{Implementing a PBL paramterization into RAMS}

E. L. McGrath-Spangler et al.

Title Page

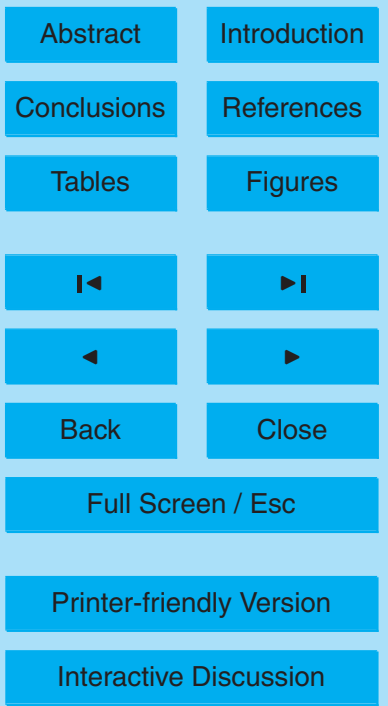

14330 
Carson, D. J.: The development of a dry inversion-capped convectively unstable boundary layer, Q. J. Roy. Meteor. Soc., 100, 450-467, 1973.

Collatz, G. J., Ball, J. T., Grivet, C., and Berry, J. A.: Physiological and environmental regulation of stomatal conductance, photosynthesis and transpiration: A model that includes a laminar boundary layer, Agr. Forest Meteorol., 54, 107-136, 1991.

Collatz, G. J., Ribas-Carbo, M., and Berry, J. A.: Coupled photosynthesis-stomatal conductance model for leaves of c-4 plants, Aust. J. Plant Physiol., 19, 519-538, 1992.

Corbin, K. D., Denning, A. S., Lu, L., Wang, J.-W., and Baker, I. T.: Possible representation errors in inversions of satellite $\mathrm{CO}_{2}$ retrieval, J. Geophys. Res., 113, D02301, doi:10.1029/2007JD0087162008.

Cotton, W. R., Pielke Sr. R. A., Walko, R. L., Liston, G. E., Tremback, C. J., Jiang, H., McAnelly, R. L., Harrington, J. Y., Nicholls, M. E., Carrio, G. G., and McFadden, J. P.: RAMS 2001: Current status and future directions, Meteorol. Atmos. Phys. 82, 5-29, 2003.

Davis, K. J., Lenschow, D. H., Oncley, S. P., Kiemle, C., Ehret, G., Giez, A., and Mann, J.: Role 15 of entrainment in surface-atmosphere interactions over the boreal forest, J. Geophys. Res., 102(D24), 29219-29230 1997.

Deardorff, J. W.: Three-dimensional numerical study of the height and mean structure of a heated planetary boundary layer, Bound.-Lay. Meteorol., 7, 81-106, 1974.

Denning, A. S., Fung, I. Y., and Randall, D. A.: Latitudinal gradient of atmospheric $\mathrm{CO}_{2}$ due to seasonal exchange with land biota, Nature, 376, 240-243, 1995.

Denning, A. S., Collatz, J. G., Zhang, C., Randall, D. A., Berry, J. A., Sellers, P. J., Colello, G. D., and Dazlich, D. A.: Simulations of terrestrial carbon metabolism and atmospheric $\mathrm{CO}_{2}$ in a general circulation model. Part 1: Surface carbon fluxes, Tellus, 48B, 521-542, 1996a.

Denning, A. S., Randall, D. A., Collatz, G. J., and Sellers, P. J.: Simulations of terrestrial carbon metabolism and atmospheric $\mathrm{CO}_{2}$ in a general circulation model. Part 2: Spatial and temporal variations of atmospheric $\mathrm{CO}_{2}$, Tellus, 48B, 543-567, 1996b.

Denning, A. S., Takahashi, T., and Friedlingstein, P.: Can a strong atmospheric $\mathrm{CO}_{2}$ rectifier effect be reconciled with a "reasonable" carbon budget?, Tellus, 51B, 249-253, 1999.

Denning, A. S., Nicholls, M., Prihodko, L., Baker, I., Vidale, P.-L., Davis, K., and Bakwin, P.: Simulated variations in atmospheric $\mathrm{CO}_{2}$ over a Wisconsin forest using a coupled ecosystematmosphere model, Glob. Change Biol., 9, 1241-1250, 2003.

Denning, A. S., Zhang, N., Yi, C., Branson, M., Davis, K., Kleist, J., and Bakwin, P.: Evaluation of modeled atmospheric boundary layer depth at the WLEF tower, Agr. Forest Meteorol.,

\section{Implementing a PBL paramterization into RAMS}

E. L. McGrath-Spangler et al.

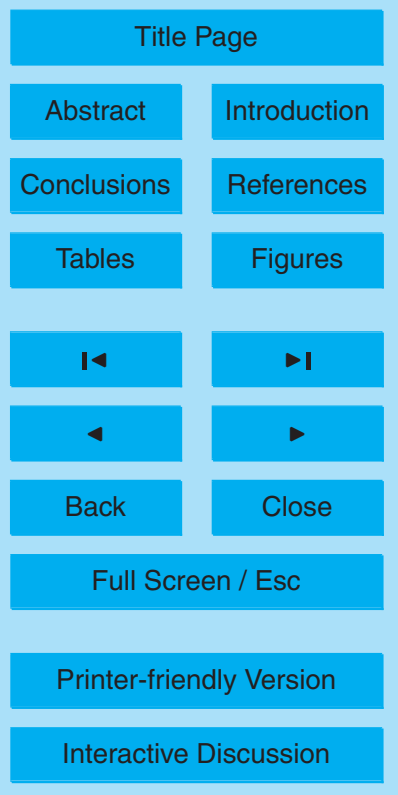


148, 206-215, 2008.

Farquhar, G. D., Caemmerer, S. V., and Berry, J. A.: A biochemical-model of photosynthetic $\mathrm{CO}_{2}$ assimilation in leaves of C-3 species, Planta, 149, 78-90, 1980.

Freitas, S. R., Longo, K., Silva Dias, M., Silva Dias, P., Chatfield, R., Fazenda, Á., and Rogrigues, L. F.: The coupled aerosol and tracer transport model to the Brazilian developments on the Regional Atmospheric Modeling System: Validation using direct and remote sensing observations, International Conference on Southern Hemisphere Meteorology and Oceanography (ICSHMO), 8, 101-107, CD-ROM, ISBN 85-17-00023-4, 2006.

Gerbig, C., Lin, J. C., Wofsy, S. C., Daube, B. C., Andrews, A. E., Stephens, B. B., Bakwin, P. S., and Grainger, C. A.: Toward constraining regional-scale fluxes of $\mathrm{CO}_{2}$ with atmospheric observations over a continent: 1 . Observed spatial variability from airborne platforms, J. Geophys. Res., 108(D24), 4756, doi:10.1029/2002JD003018, 2003a.

Gerbig, C., Lin, J. C., Wofsy, S. C., Daube, B. C., Andrews, A. E., Stephens, B. B., Bakwin, P. S., and Grainger, C. A.: Toward constraining regional-scale fluxes of $\mathrm{CO}_{2}$ with atmospheric observations over a continent: 2 . Analysis of COBRA data using a receptor-oriented framework, J. Geophys. Res., 108(D24), 4757, doi:10.1029/2002JD003018, 2003b.

Gurney, K. R., Law, R. M., Denning, A. S., Rayner, P. J., Baker, D., Bousquet, P., Bruhwiler, L., Chen, Y.-H., Ciais, P., Fan, S., Fung, I. Y., Gloor, M., Heimann, M., Higuchi, K., John, J., Maki, T., Maksyutov, S., Masarie, K., Peylin, P., Prather, M., Pak, B. C., Randerson, J., Sarmiento, J., Taguchi, S., Takahashi, T., and Yuen, C.-W.: Towards robust regional estimates of $\mathrm{CO}_{2}$ sources and sinks using atmospheric transport models, Nature, 415, 626-630, 2002.

Harrington J. Y.: The effects of radiative and microphysical processes on simulated warm and transition season Arctic stratus, PhD Diss., Atmospheric Science Paper No. 637, Colorado Statue University, Department of Atmospheric Science, Fort Collins, CO 80523, 289 pp., 1997.

Medvigy, D., Moorcroft, P. R., Avissar, R., and Walko, R. L.: Mass conservation and atmospheric dynamics in the Regional Atmospheric Modeling System (RAMS), Environ. Fluid Mech., 5, 109-134, 2005.

Mellor, G. L. and Yamada, T.: Development of a turbulence closure model for geophysical fluid 30 problems, Rev. Geophys., 20, 851-875, 1982.

Nicholls, M. E., Denning, A. S., Prihodko, L., Vidale, P.-L., Baker, I., Davis, K., and Bakwin, P.: A multiple-scale simulation of variations in atmospheric carbon dioxide using a coupledbiosphere-atmospheric model, J. Geophys. Res., 109, D18117, doi:10.1029/2003JD00482,

\section{Implementing a PBL paramterization into RAMS}

E. L. McGrath-Spangler et al.

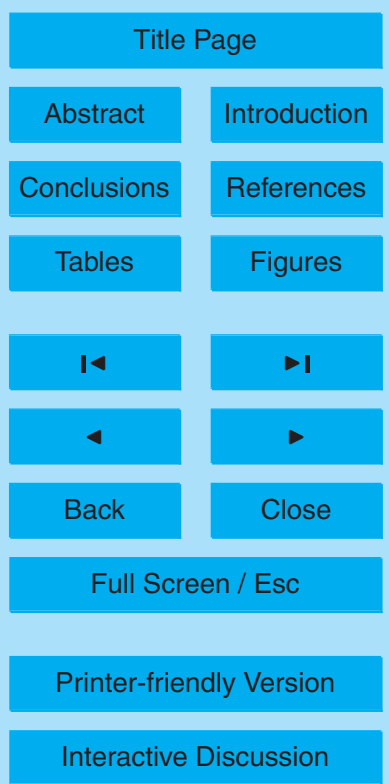


2004.

Pielke, R. A.: A three-dimensional numerical model of the sea breezes over south Florida, Mon. Weather Rev., 102, 115-139, 1974.

Pielke, R. A.: Overlooked scientific issues in assessing hypothesized greenhouse gas warming, Environ. Software, 6, 100-107, 1991.

Pielke, R. A., Cotton, W. R., Walko, R. L., Tremback, C. J., Lyons, W. A., Grasso, L. D., Nicholls, M. E., Moran, M. D., Wesley, D. A., Lee, T. J., and Copeland, J. H.: A comprehensive meteorological modeling system RAMS, Meteorol. Atmos. Phys., 49, 69-91, 1992.

Rayment, R. and Readings, C. J.: A case study of the structure and energetics of an inversion, 10 Q. J. Roy. Meteor. Soc., 100, 221-233, 1974.

Sayler, B. J. and Breidenthal, R. E.: Laboratory simulations of radiatively induced entrainment in stratiform clouds, J. Geophys. Res., 103, 8827-8837, 1998.

Sellers, P. J., Mintz, Y., Sud, Y. C., and Dalcher, A.: A simple biosphere model (SiB) for use within general circulation models, J. Atmos. Sci., 43, 505-531, 1986.

15 Sellers, P. J., Randall, D. A., Collatz, G. J., Berry, J. A., Field, C. B., Dazlich, D. A., Zhang, C., Collelo, G. D., and Bounoua, L.: A revised land surface parameterization (SiB2) for atmospheric GCMs, Part 1: Model formulation, J. Climate, 9, 676-705, 1996.

Smagorinsky, J. S.: General circulation experiments with the primitive equations. 1: The basic experiment, Mon. Weather Rev., 91, 99-164, 1963.

20 Sullivan, P. P., Moeng, C.-H., Stevens, B., Lenschow, D. H., and Mayer, S. D.: Structure of the entrainment zone capping the convective atmospheric boundary layer, J. Atmos. Sci., 55, 3042-3064, 1998.

Stevens, D. E. and Bretherton, C. S.: Effects of resolution on the simulation of stratocumulus entrainment, Q. J. Roy. Meteor. Soc., 125, 425-439, 1999.

25 Stull, R. B.: The energetics of entrainment across a density interface, J. Atmos. Sci., 33, 12601267, 1976.

Stull, R. B.: An introduction to boundary layer meteorology, Kluwer Academic Publishers, Norwell, MA. $666,1988$.

Tripoli, G. J. and Cotton, W. R.: The Colorado State University thee-dimensional cloud/mesoscale model - 1982. Part I: General theoretical framework and sensitivity experiments, J. Rech. Atmos., 16, 185-220, 1982.

Walko, R. L., Tremback, C. J., Panetta, J., Freitas, S., and Fazenda, A. L.: RAMS Regional Atmospheric Modeling System version 5.0 model input namelist parameters,

\section{Implementing a PBL paramterization into RAMS}

E. L. McGrath-Spangler et al.

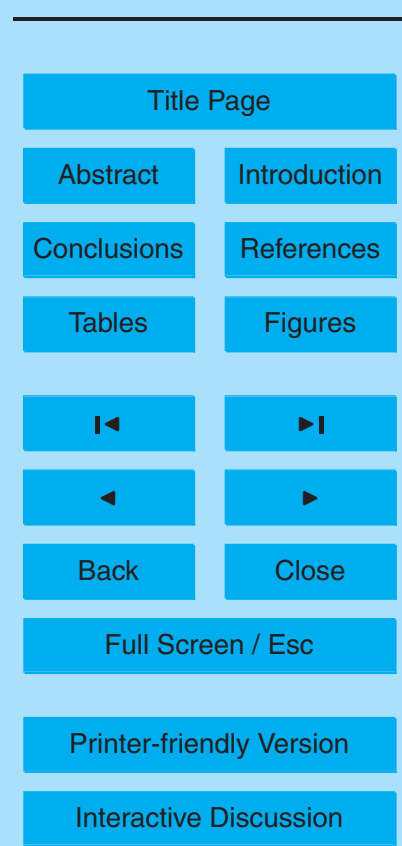


http://www.cptec.inpe.br/brams/input_namelist.shtml (last access: 8 December 2007), 2002.

Wang, J.-W., Denning, A. S., Lu, L., Baker, I. T., Corbin, K. D., and Davis, K. J.: Observations and simulations of synoptic, regional, and local variations in atmospheric $\mathrm{CO}_{2}$, J. Geophys. Res., 112, D04108, doi:10.1029/2006JD007410, 2007.

5 Willis, G. E. and Deardorff, J. W.: A laboratory model of the unstable planetary boundary layer, J. Atmos. Sci., 31, 1297-1307, 1974.

Yi, C., Davis, K. J., Berger, B. W., and Bakwin, P. S.: Long-term observations of the dynamics of the continental planetary boundary layer, J. Atmos. Sci., 58, 1288-1299, 2001.

Zhang, N.: Observations and simulations of the planetary boundary layer at a tall tower in northern Wisconsin. Master's thesis, Colorado State University, Department of Atmospheric Science, Fort Collins, CO 80523, 71, 2002.

Zupanski, D., Denning, A. S., Uliasz, M., Zupanski, M., Schuh, A. E., Rayner, P. J., Peters, W., and Corbin, K.: Carbon flux bias estimation employing Maximum Likelihood Ensemble Filter (MLEF), J. Geophys. Res., 112, D17107, doi:10.1029/2006JD008371, 2007.

Zupanski, M.: Maximum likelihood ensemble filter: Theoretical aspects, Mon. Weather Rev., 133, 1710-1726, 2005.

\section{ACPD}

$8,14311-14346,2008$

\section{Implementing a PBL paramterization into \\ RAMS}

E. L. McGrath-Spangler et al.

Title Page

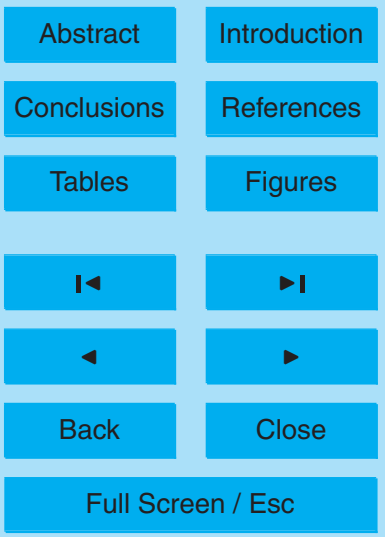

Printer-friendly Version

Interactive Discussion 


\section{ACPD}

8, 14311-14346, 2008

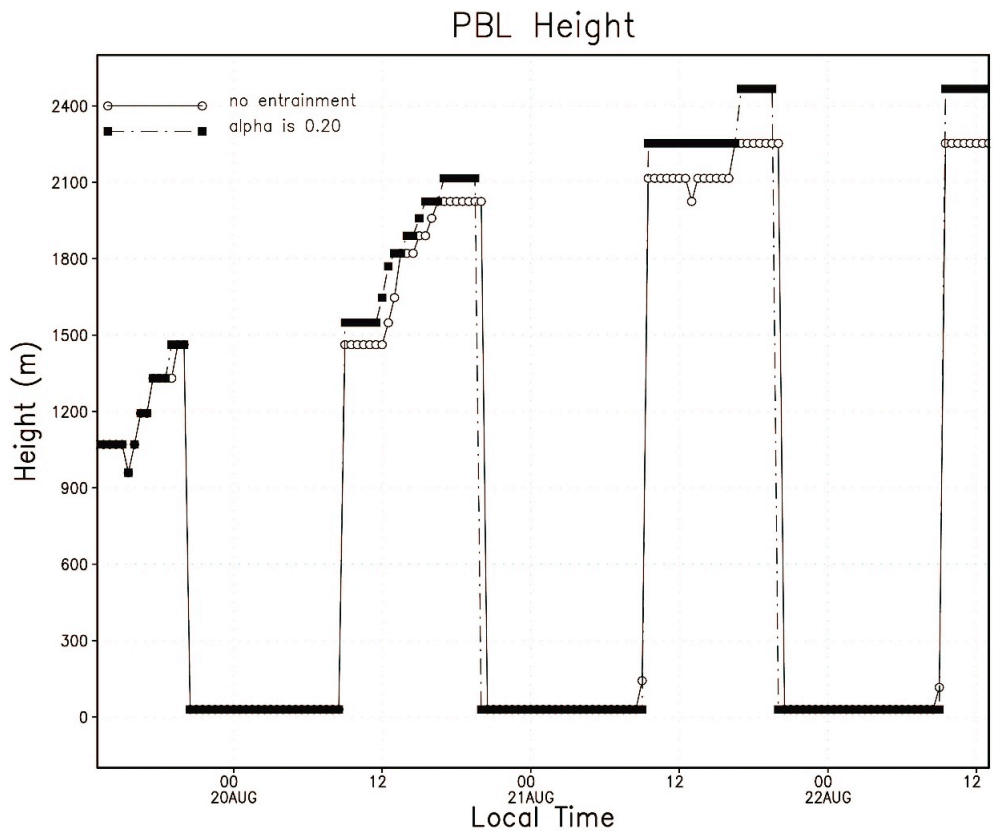

Implementing a PBL paramterization into RAMS

E. L. McGrath-Spangler et al.

Title Page

Abstract

Conclusions

Tables

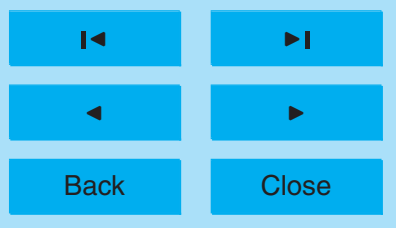

Full Screen / Esc

Printer-friendly Version

Interactive Discussion 


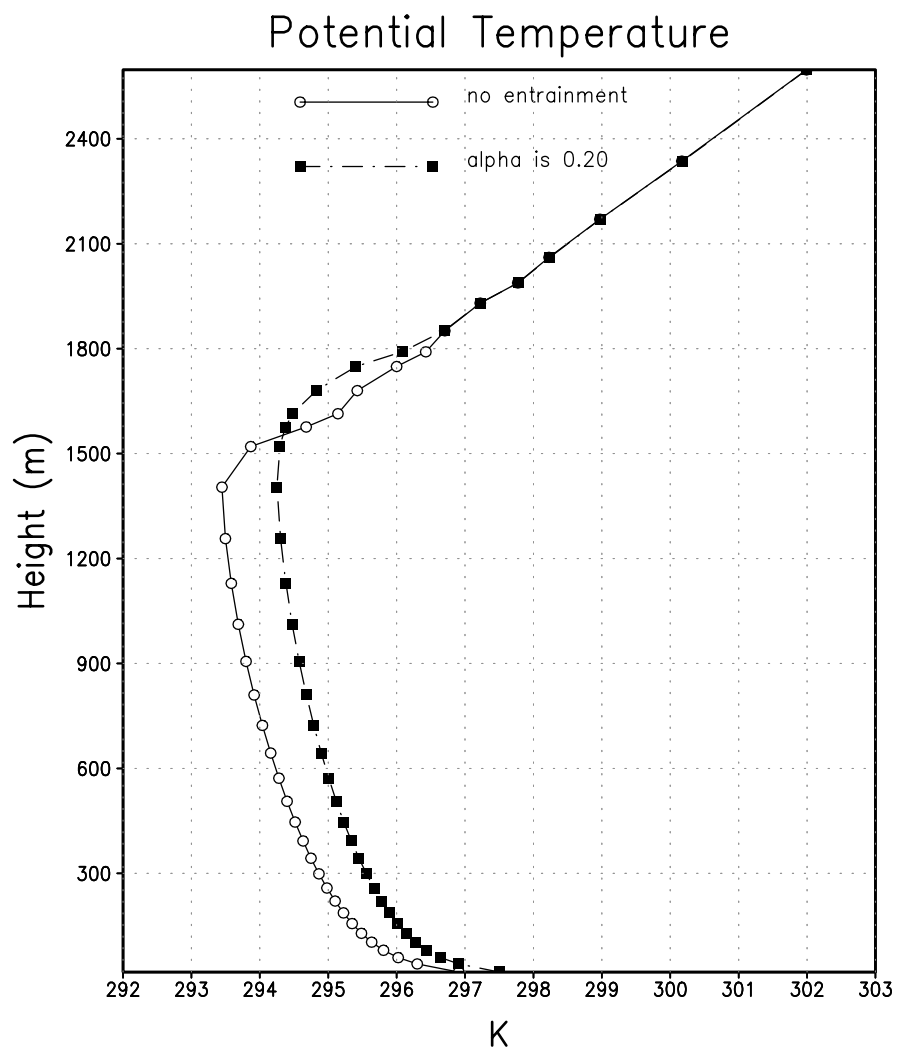

8, 14311-14346, 2008

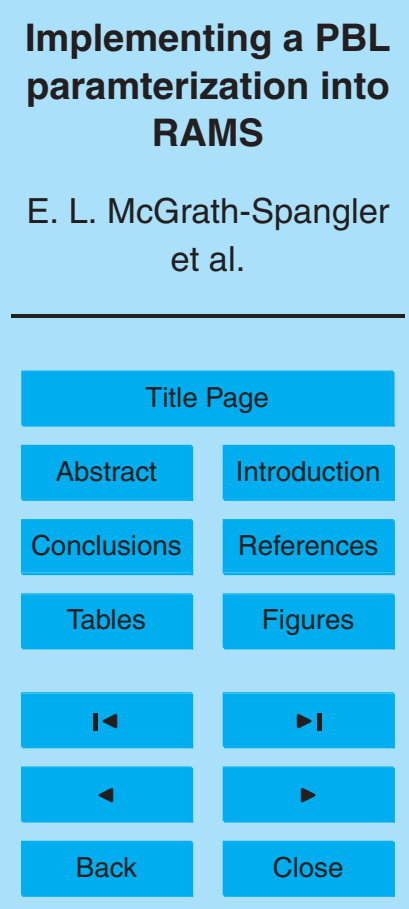

Full Screen / Esc

Fig. 2. Profile of potential temperature for both the entraining and control cases on 20 August 2004 at 12 pm LT.

Printer-friendly Version

Interactive Discussion 


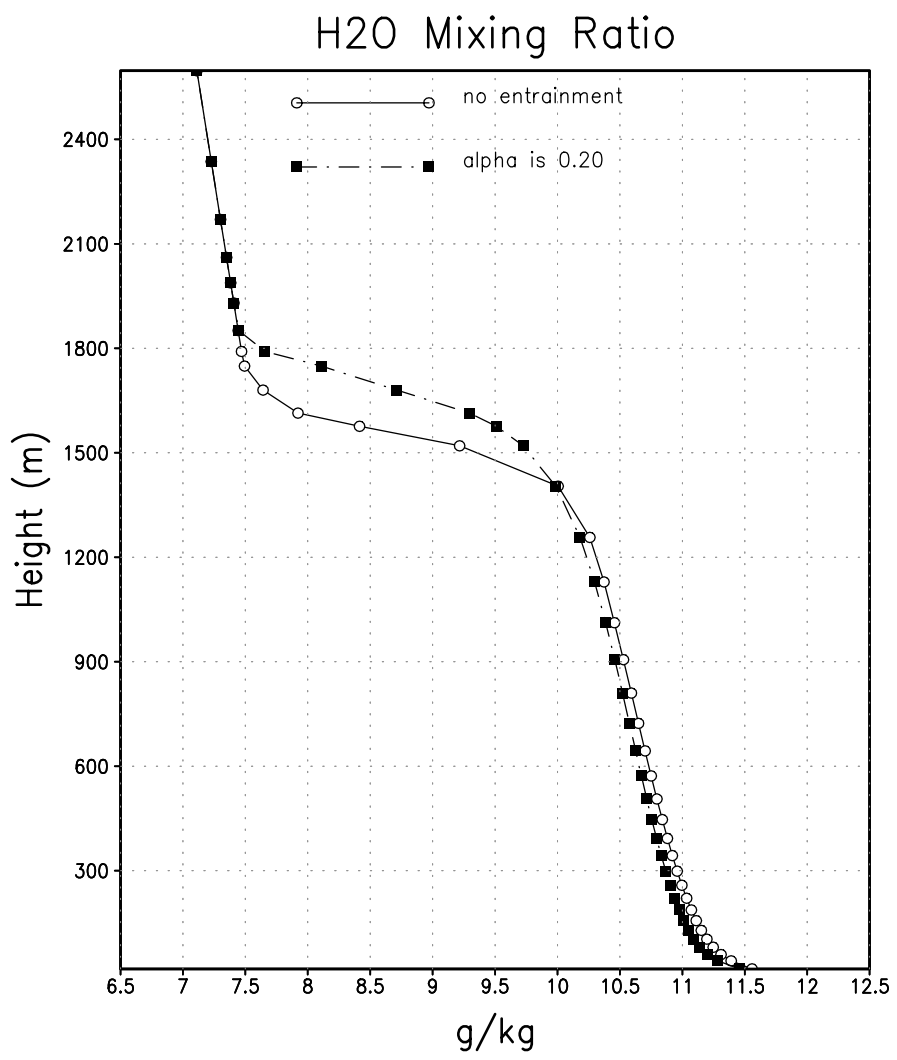

Fig. 3. Profile of water vapor mixing ratio for both the entraining and control cases on 20 August 2004 at 12 pm LT.
8, 14311-14346, 2008

\section{Implementing a PBL paramterization into RAMS \\ E. L. McGrath-Spangler et al. \\ Title Page

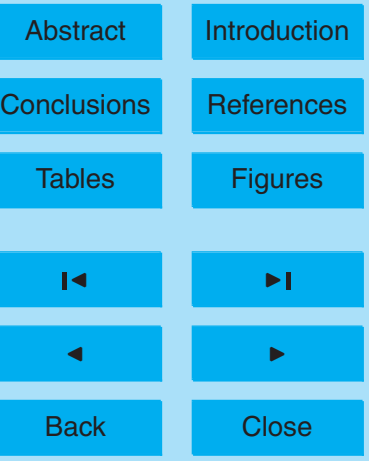

Full Screen / Esc

Printer-friendly Version

Interactive Discussion 


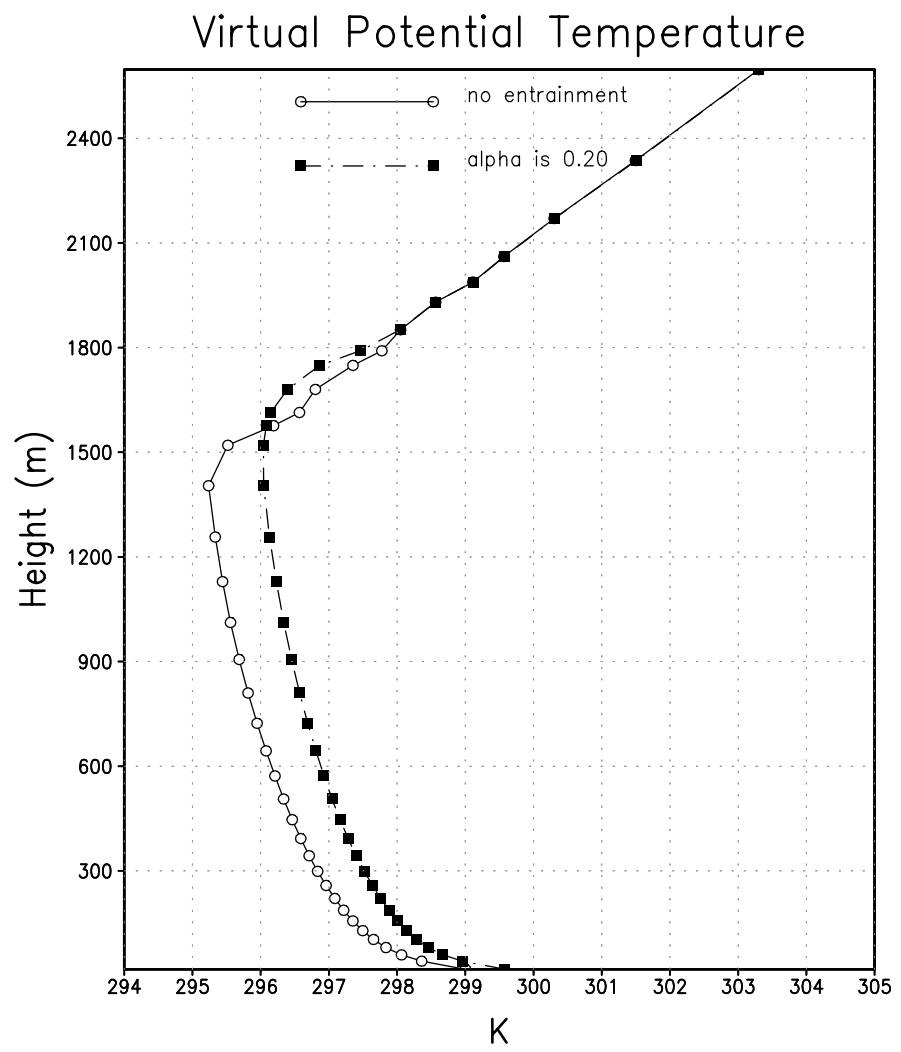

$8,14311-14346,2008$

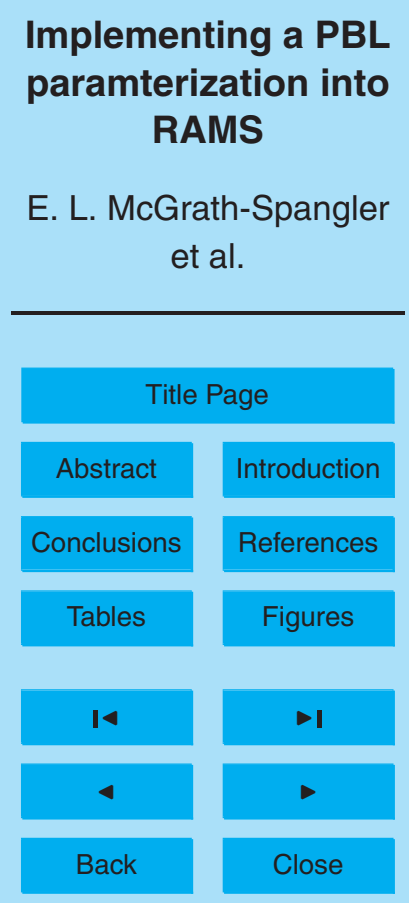

Full Screen / Esc

Fig. 4. Profile of virtual potential temperature for both the entraining and control cases on 20 August 2004 at 12 pm LT. 


\section{ACPD}

$8,14311-14346,2008$

Potential Temperature

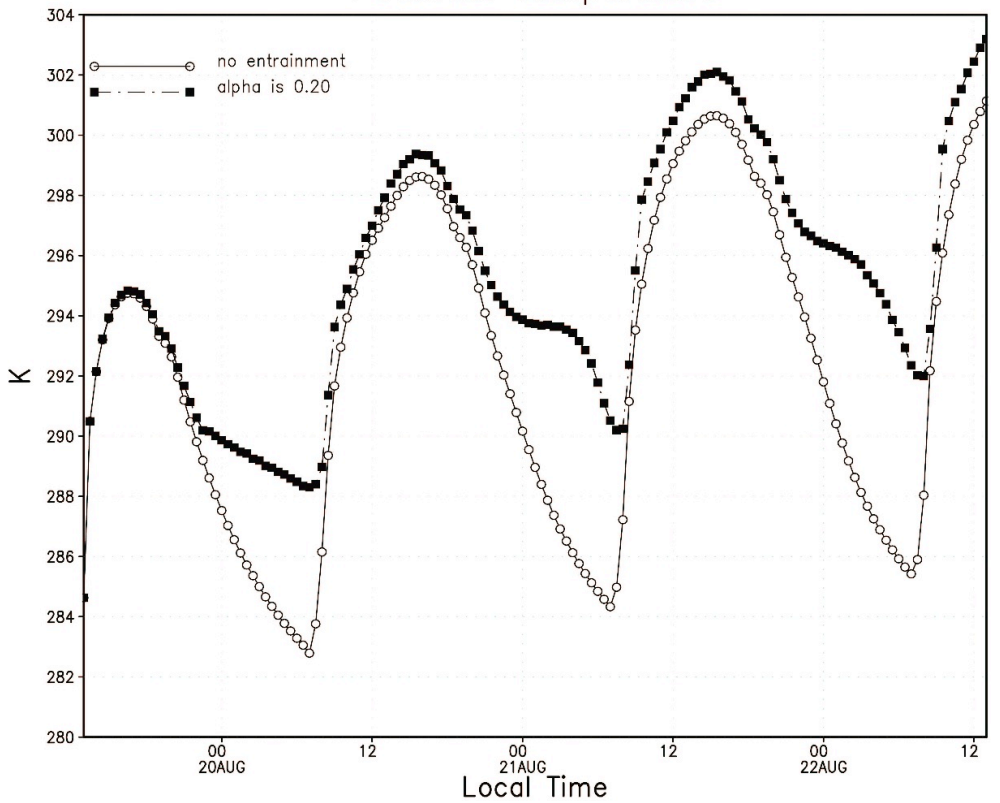

Fig. 5. Temporal evolution of potential temperature in the lowest atmospheric model level for the entraining and control cases.

\section{Implementing a PBL paramterization into RAMS \\ E. L. McGrath-Spangler et al. \\ Title Page

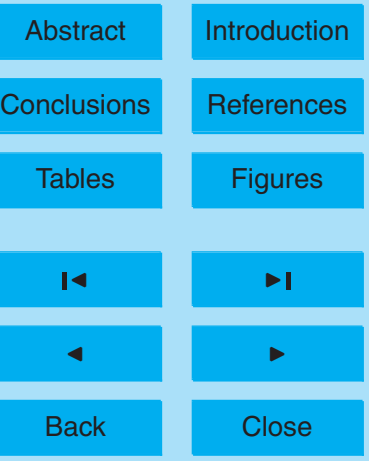 \\ Full Screen / Esc}

Printer-friendly Version

Interactive Discussion 


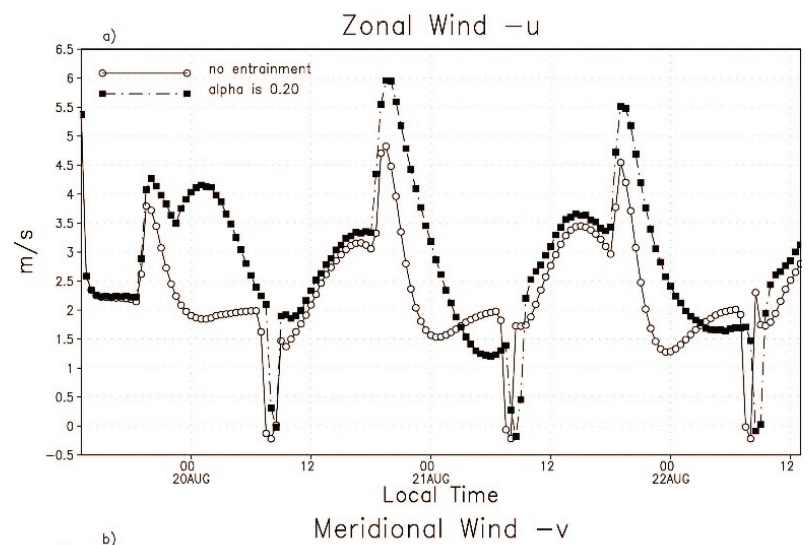

ACPD

8, 14311-14346, 2008

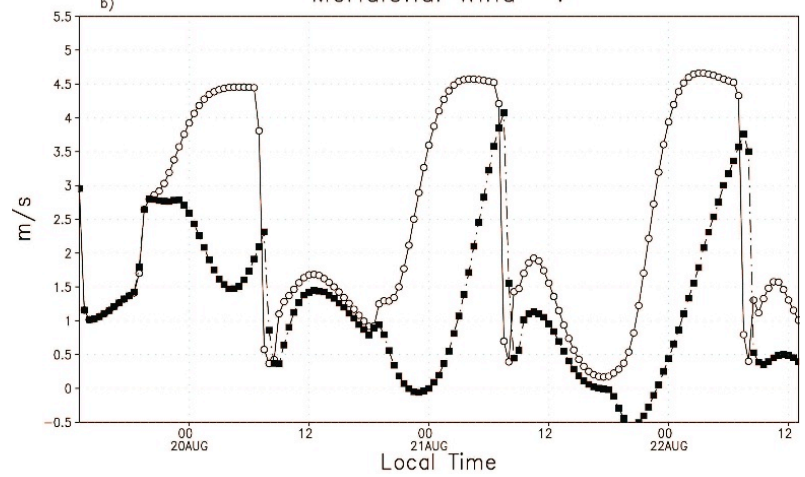

Implementing a PBL paramterization into

RAMS

E. L. McGrath-Spangler et al.

Title Page

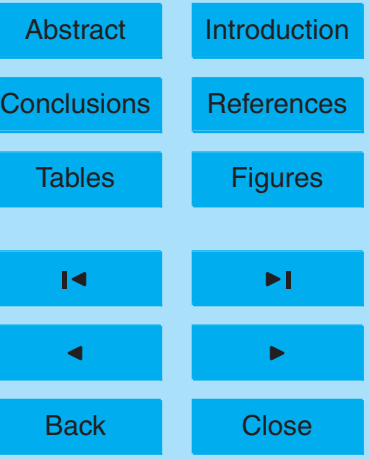

Full Screen / Esc

Fig. 6. Temporal evolution of the zonal (a) and meridional (b) winds in the lowest atmospheric model level for the entraining and control cases.

Printer-friendly Version

Interactive Discussion 


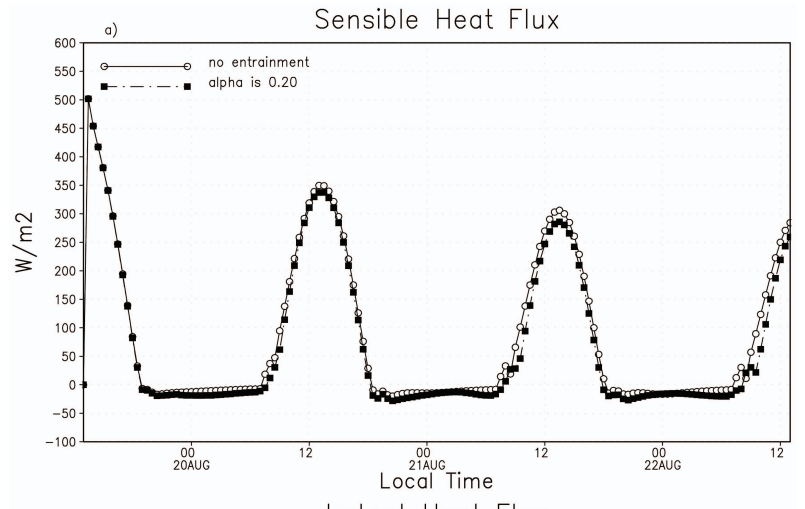

\section{ACPD}

8, 14311-14346, 2008

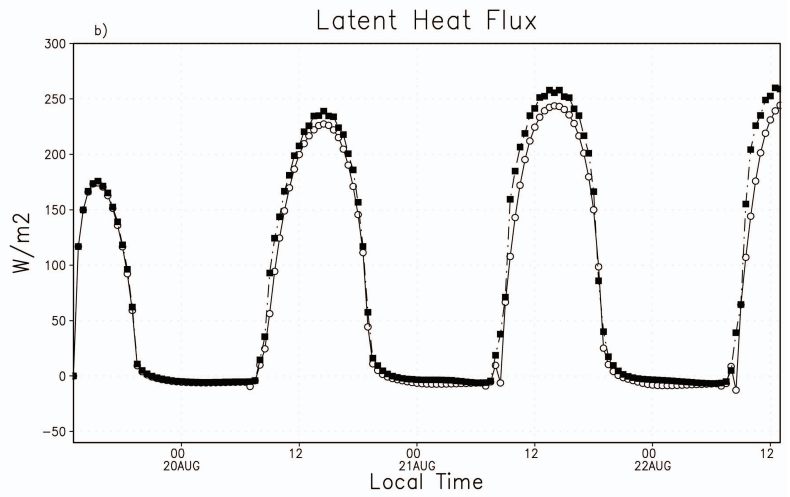



Full Screen / Esc

Printer-friendly Version

Interactive Discussion 


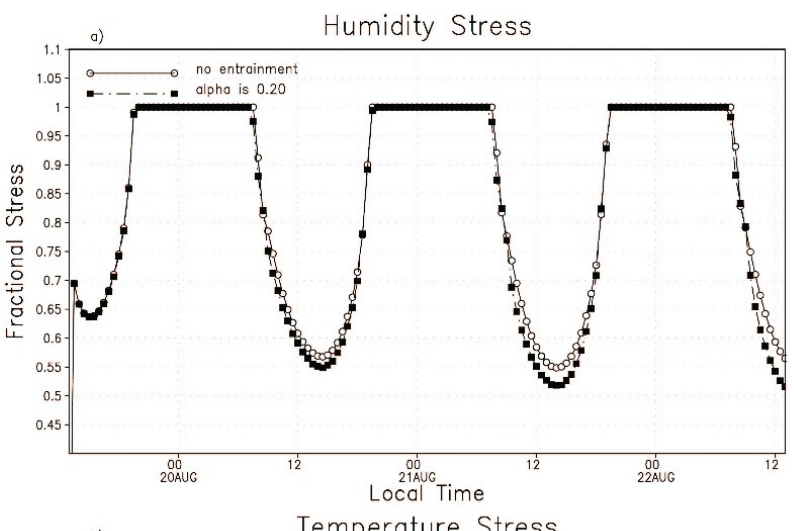

\section{ACPD}

$8,14311-14346,2008$

\section{Implementing a PBL paramterization into \\ RAMS \\ E. L. McGrath-Spangler et al. \\ Title Page

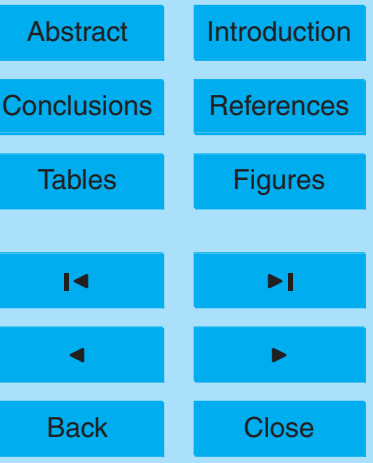

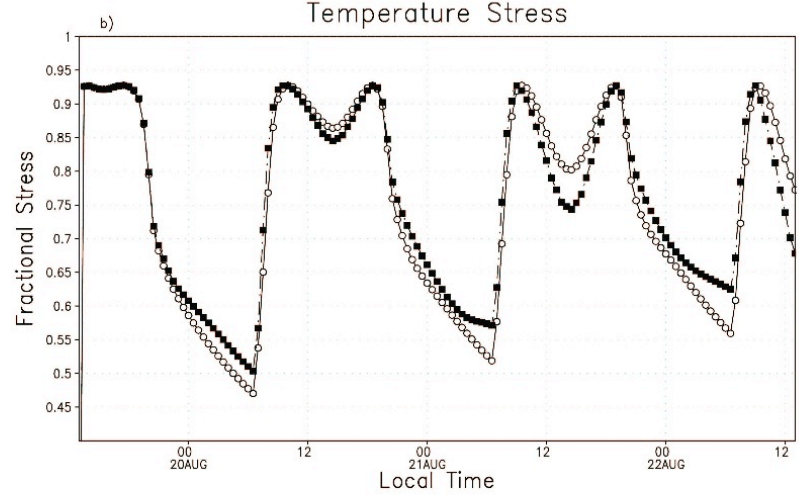

Full Screen / Esc

Fig. 8. Temporal evolution of vegetative stress factors for the entraining and control cases. (a) Humidity stress (b) Temperature stress. 


\section{ACPD}

$8,14311-14346,2008$
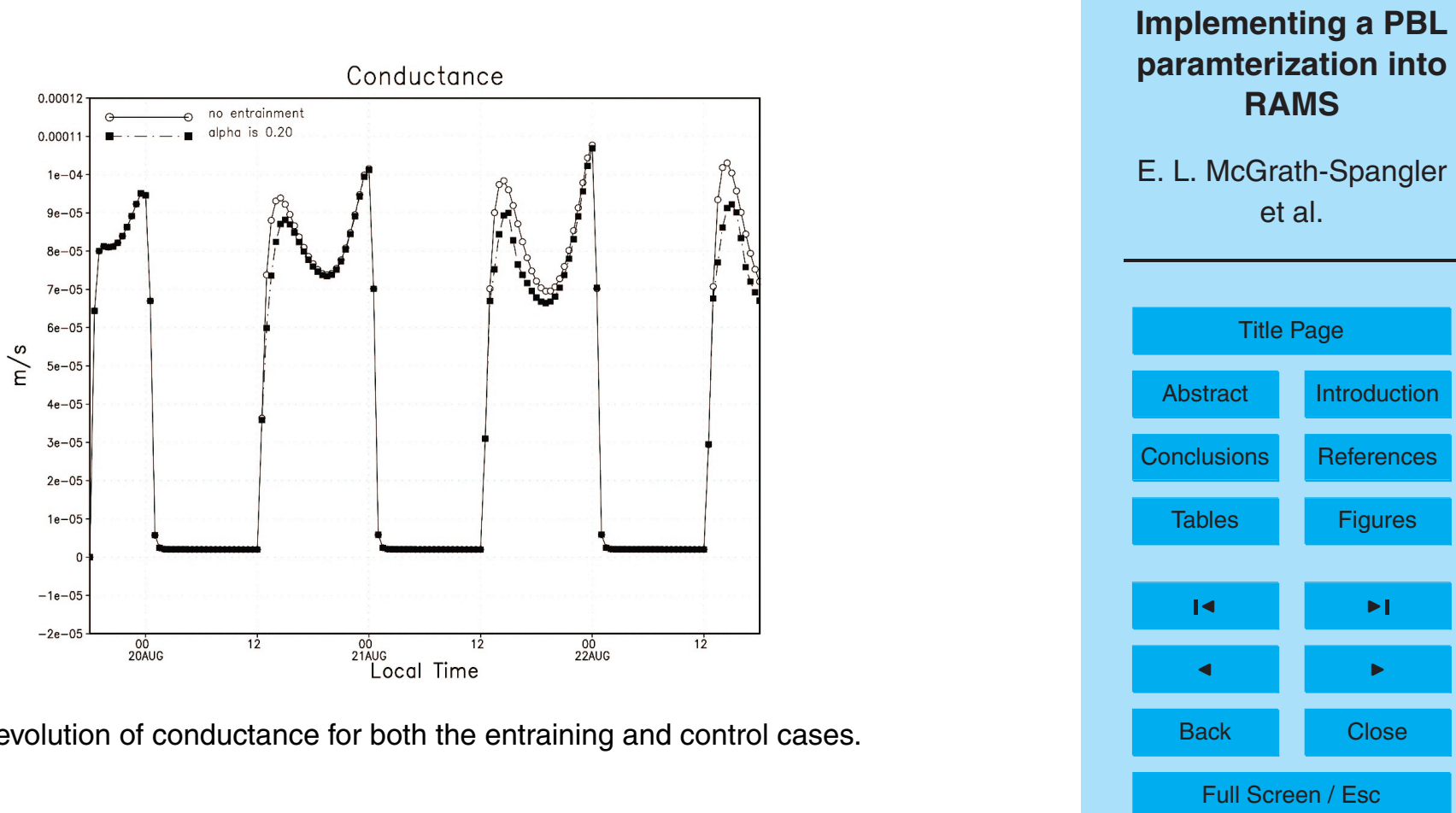

Fig. 9. Temporal evolution of conductance for both the entraining and control cases.

Full Screen / Esc

Printer-friendly Version

Interactive Discussion 


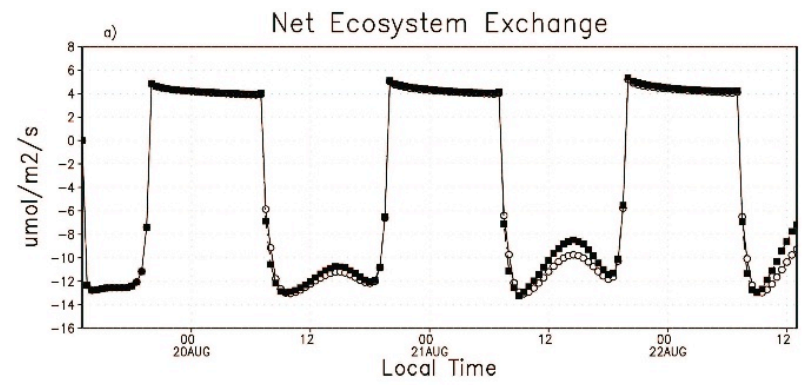

\section{ACPD}
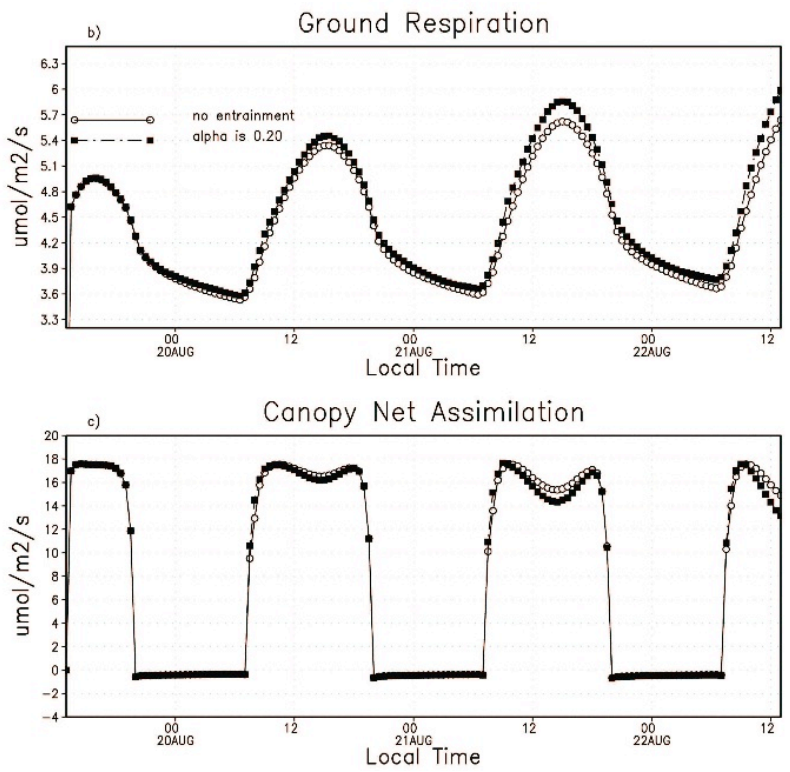

$8,14311-14346,2008$

Implementing a PBL paramterization into RAMS

E. L. McGrath-Spangler et al.

Title Page

Abstract

Introduction

Conclusions

References

Tables

Figures

14



Back

Full Screen / Esc

Fig. 10. Temporal evolution of NEE (a), ground respiration (b), and canopy net assimilation (c) for the entraining and control cases.

Printer-friendly Version

Interactive Discussion 


\section{ACPD}

$8,14311-14346,2008$



Implementing a PBL paramterization into RAMS

E. L. McGrath-Spangler et al.

Title Page

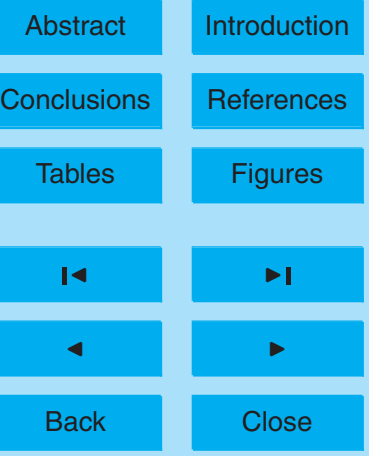

Full Screen / Esc

Fig. 11. Temporal evolution of carbon dioxide concentration in the lowest atmospheric model level for the entraining and control cases.

Printer-friendly Version

Interactive Discussion 

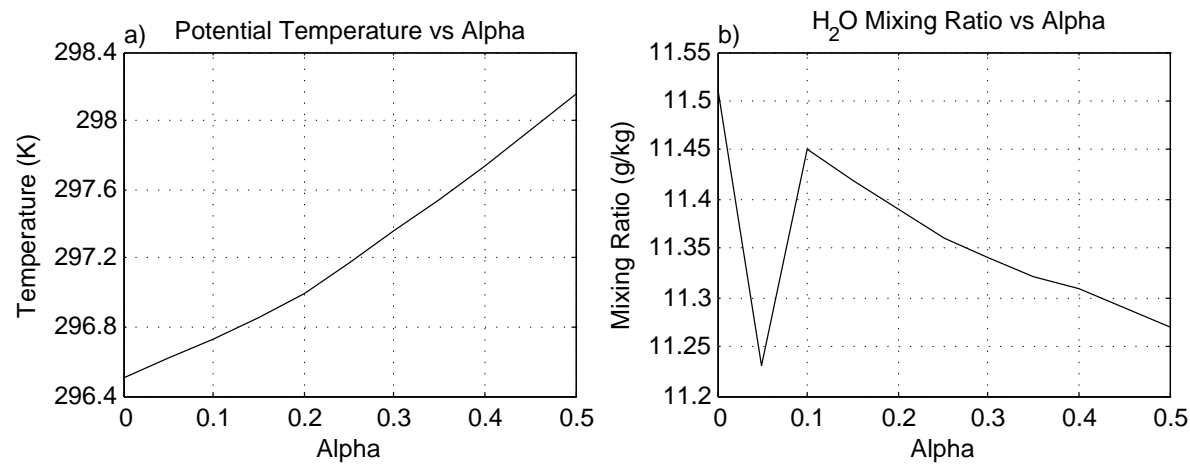

8, 14311-14346, 2008
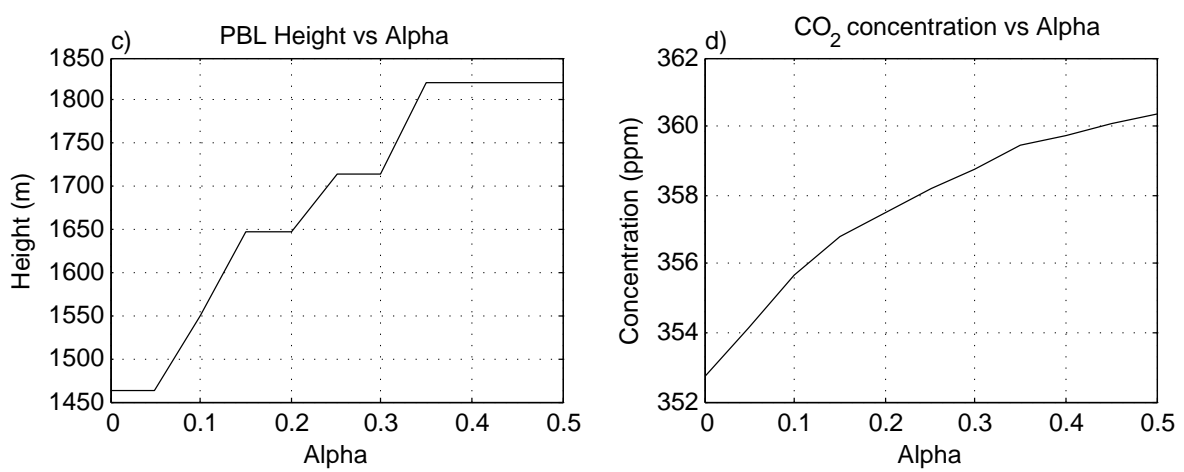

Fig. 12. Sensitivity of potential temperature (a), water vapor mixing ratio (b), PBL depth (c), and $\mathrm{CO}_{2}$ concentration (d) in the lowest model level to $\alpha$. Values taken from 12:00 LT on the second day of simulation.

Implementing a PBL paramterization into RAMS

E. L. McGrath-Spangler et al.

Title Page

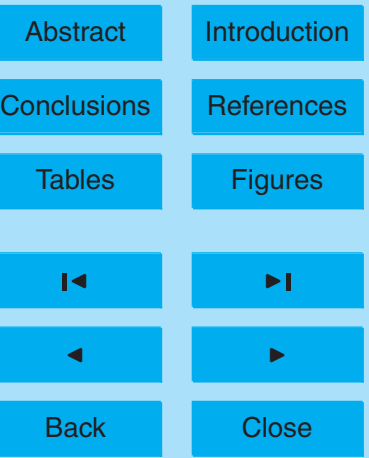

Full Screen / Esc

Printer-friendly Version

Interactive Discussion 